University of Rhode Island

DigitalCommons@URI

Open Access Master's Theses

2009

\title{
An Examination of Mindfulness and Substance Use Among College Students
}

Anne Christie Fernandez

University of Rhode Island

Follow this and additional works at: https://digitalcommons.uri.edu/theses

\section{Recommended Citation}

Fernandez, Anne Christie, "An Examination of Mindfulness and Substance Use Among College Students" (2009). Open Access Master's Theses. Paper 1637.

https://digitalcommons.uri.edu/theses/1637

This Thesis is brought to you for free and open access by DigitalCommons@URI. It has been accepted for inclusion in Open Access Master's Theses by an authorized administrator of DigitalCommons@URI. For more information, please contact digitalcommons-group@uri.edu. 
AN EXAMINATION OF MINDFULNESS AND SUBSTANCE USE AMONG COLLEGE STUDENTS

BY

ANNE CHRISTIE FERNANDEZ

A THESIS SUBMITTED IN PARTIAL FULFILLMENT OF THE REQUIREMENTS FOR THE DEGREE OF

MASTER OF ARTS

IN

CLINICAL PSYCHOLOGY

UNIVERSITY OF RHODE ISLAND

2009 


\section{Abstract}

A growing body of research indicates that mindfulness-based therapies may be useful for treating substance abuse. However, the incorporation of mindfulness into substance abuse treatment is limited by a lack of basic research in this area. For example, instruments designed to measure mindfulness vary widely in content and validity and the fundamental relationships among mindfulness, alcohol use, and drug use are not well-understood. Accordingly, this study sought to validate an emerging measure of mindfulness, the Five Facet Mindfulness Questionnaire (FFMQ), and examine its relationship with substance use among a sample of 316 current or former college students. The purported factor structure of the FFMQ was examined using a series of confirmatory factor analyses, and structural equation modeling was used to measure the relationship between mindfulness and substance use. Consistent with past research, results supported the five-factor structure of the FFMQ. However, a hierarchical factor analysis did not support the existence of a single overarching mindfulness factor. Two of the FFMQ factors were negatively related to alcohol use ( $p$ $<.05$ ), and three factors held a marginally significant negative relationship with alcohol-related consequences $(\mathrm{p}<.10)$. Attempts to examine the relationship between mindfulness and other drug use were abandoned because of low base rates. These results support the five factor structure of the FFMQ, but additional psychometric testing is needed to determine whether all factors of the FFMQ represent mindfulness as a single overarching construct. The results reported here can be used inform the burgeoning development of mindfulness-based addiction treatments. 


\section{Acknowledgements}

Special thanks to my Major Professor, Dr. Mark Wood, as well as my

committee members, Lynda Stein, Judith Swift, and committee chair, Ginette Ferszt. I would also like to acknowledge the University of Rhode Island and the Psychology Department for their ongoing support. 
Table of Contents:

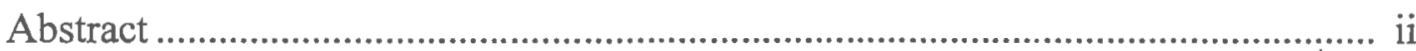

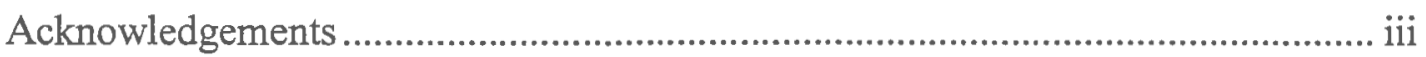

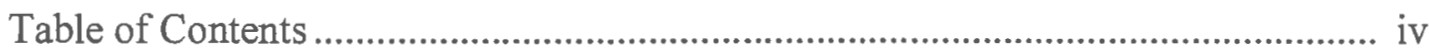

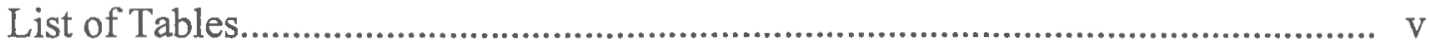

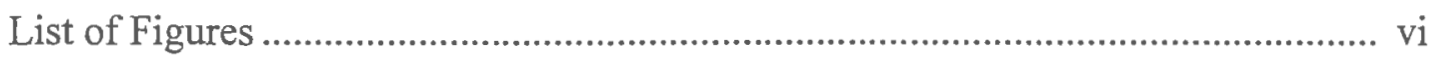

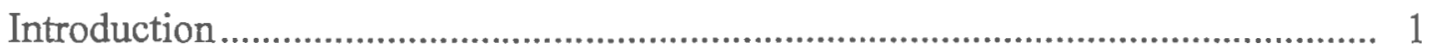

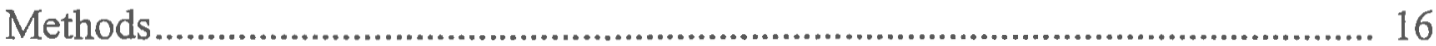

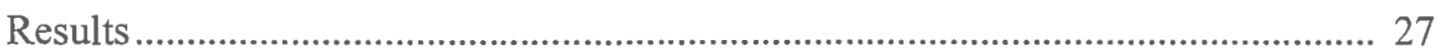

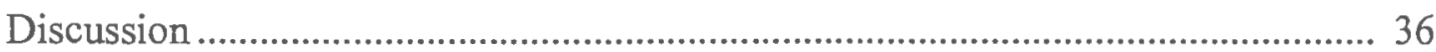

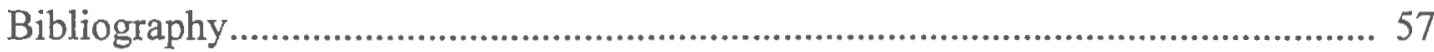




\section{Lists of Tables}

Table 1: Sample Items from FFMQ Factors

Table 2: Predicted Relationships Among the FFMQ and Related Constructs.......... 48

Table 3: CFA Fit Indices.................................................................................... 50

Table 4: Correlations among the FFMQ and Related Constructs .......................... 51 


\section{List of Figures}

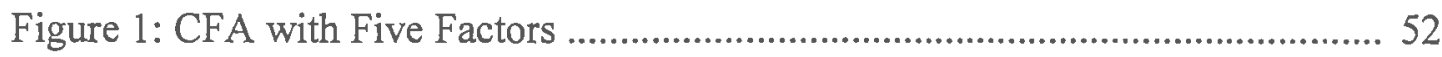

Figure 2: CFA with Parcel 7 Removed ................................................................... 53

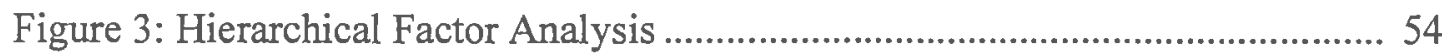

Figure 4: Relationships Among the FFMQ, Alcohol Use, and Alcohol-Related Consequences....................................................... 55

Figure 5: Relationships Among the FFMQ and Drug Use ................................... 56 


\section{Introduction}

What is Mindfulness?

Mindfulness has been defined as "the clear and single-minded awareness of what actually happens to us and in us, at the successive moments of perception" (Mahathera, 1971, p. 103). A two-part operational definition of mindfulness has been proposed and includes "the self-regulation of attention so that it is maintained on immediate experience, thereby allowing for increased recognition of mental events in the present moment" and "adopting a particular orientation toward one's experiences in the present moment, an orientation that is characterized by curiosity, openness, and acceptance" (Bishop et al., 2004, p. 232). Mindfulness is frequently practiced as part of formal sitting or walking meditation in the Buddhist tradition. These meditations often involve affixing the attention on the experience of the present moment at the level of thoughts, feelings and/or sensations, but may also employ such concentrative practices as focusing on an object or the breath. In the context of normal everyday life mindfulness involves cultivating the ability to stay present through all of life's experiences with openness and objectivity. In this sense mindfulness takes on an unassuming but central role in cultivating psychological balance, or equanimity within Buddhist philosophy (Mahathera, 1971).

\section{Mindfulness and Psychology}

In an effort to understand mindfulness in the broader context of personality, past studies have examined the association between mindfulness and a myriad of personality and psychological variables (Baer, Smith, \& Allen, 2004; Baer, Smith, Hopkins, Krietemeyer, \& Toney, 2006; Brown \& Ryan, 2003; Lau et al., 2006; 
Walach, Buchheld, Buttenmüller, Kleinknecht, \& Schmidt, 2006). Positive associations between mindfulness and self-esteem, optimism, life satisfaction, and positive affect have all been reported (Brown \& Ryan, 2003). Negative correlations between mindfulness and depression, anxiety, self-consciousness (Brown \& Ryan, 2003), and psychological distress (Baer et al., 2004) have also been reported. The above pattern of relationships suggests that mindfulness is related to psychological well-being and that individuals high in mindfulness may be less likely to experience a variety of psychological stressors. In terms of the major dimensions of personality, mindfulness is negatively related to neuroticism and is unrelated to extraversion (Baer et al., 2006; Brown \& Ryan, 2003). Other broad-band measures of personality including openness to experience and novelty seeking are also positively related to mindfulness indicating more mindful individuals have a greater tendency to seek out and enjoy new experiences (Baer et al., 2006; Brown \& Ryan, 2003; Lau et al., 2006). Mindfulness is also related to measures of cognitive functioning. More mindful individuals report less cognitive errors due to inattention (Herndon, 2008; Lau et al., 2006), report being less absent-minded (Baer et al., 2006), and have a higher propensity to engage in deep thinking and enjoy cognitive oriented activities (Brown \& Ryan, 2003).

- The clear association between mindfulness and enhanced psychological functioning has led naturally to its incorporation into numerous treatments for mental and physical health. To date, mindfulness-based interventions have led to reductions in chronic pain (Kabat-Zinn, Lipworth, \& Burney, 1985), stress (Shapiro, Schwartz, \& Bonner, 1998), depressive relapse (Teasdale et al., 2000; Williams, Russell, \& Russell, 
2008), and suicidal behavior (Linehan, Armstrong, Suarez, \& Allmon, 1991) relative to control conditions. The Mindfulness Based Stress Reduction Program (MBSR; Kabat-Zinn, Massion, Kristeller, \& Peterson, 1992) is the most widely disseminated mindfulness-based treatment to date. Recent estimates indicate MBSR has been implemented at more than 240 locations throughout the United States (Salmon, Santorelli, \& Kabat-Zinn, 1998). The program is designed to help ease the psychological and physical difficulty of living with chronic pain and illness. In MBSR participants receive training in meditation and instruction on how to incorporate the concepts of mindfulness into everyday life. Randomized controlled trials indicate MBSR, has led to reductions in physical and psychological distress (Shapiro, Bootzin, Figueredo, Lopez, \& Schwartz, 2003; Speca, Carlson, Goodey, \& Angen, 2000; Weissbecker et al., 2002), increases in sleep quality (Shapiro et al., 2003), and reductions in mood disturbance (Speca et al., 2000).

In the behavioral and cognitive-behavioral tradition, mindfulness is an integral component of many emerging behavioral treatments (Hayes, 2004). These include Acceptance and Commitment Therapy (Hayes, Strosahl, \& Wilson, 1999), Dialectical Behavior Therapy (Linehan, 1987), Mindfulness Based Cognitive Therapy (Segal, Williams, \& Teasdale, 2002), and some lesser-known techniques such as MindfulnessBased Relapse Prevention for substance abuse (Marlatt, 2002; Witkiewitz, Marlatt, \& Walker, 2005). These therapies, also referred to as "third-wave behavioral/cognitivebehavioral therapies" are distinct from their predecessors because they emphasize changing the context and experience of psychological phenomena rather than changing the content of thoughts and feelings (Hayes, 2004). Mindfulness fits well 
within this treatment modality because it can be conceptualized as a "cognitive mode" in which distressing thoughts and feelings can take place and be observed without personal judgment (Segal, Teasdale, \& Williams, 2004) The ability to objectively observe one's own thoughts without judging them as good or bad/right or wrong is believed to enhance psychological well-being and has also been described as a type of meta-cognition (Teasdale et al., 2002). Treatments which enhance meta-cognitive awareness of negative thoughts have been shown to reduce the likelihood of depressive relapse in one randomized controlled trial (Teasdale et al., 2002).

\section{Mindfulness and Substance Abuse}

Recently, there has been an increasing interest in using mindfulness as a tool to treat substance abuse (Alterman, Koppenhaver, Mulholland, Ladden, \& Baime, 2004; Bowen et al., 2006; Breslin, Zack, \& McMain, 2002; Groves \& Farmer, 1994). Numerous conceptual papers have presented theoretical frameworks for combining mindfulness with cognitive behavioral treatments for addiction (Breslin et al., 2002; Hoppes, 2006; Witkiewitz et al., 2005). Mindfulness-Based Cognitive Therapy (Teasdale et al., 2000) for depression has also been proposed as a potentially efficacious way to treat co-occuring substance use and mood disorders (Hoppes, 2006). Currently, a Mindfulness-Based Relapse Prevention Program for substance use disorders is in development (Witkiewitz et al., 2005). Mindfulness and mindfulnessbased meditations are theorized to aid in the recovery from substance abuse by increasing awareness of craving and triggers for drug use (Marlatt, 2002). In addition, mindfulness practice is believed to increase psychological health and act as an alternative to "mindless" compulsive behaviors (Marlatt 2002; Witkiewitz et al., 2005) 
Despite the general enthusiasm among researchers regarding the potential therapeutic role of mindfulness in treating substance abuse only a small number of studies exist on this topic. Moreover, methodological constraints of these studies limit the capacity to generalize findings. These limitations include a lack of randomized controlled designs, small sample sizes, and inattention to critical measurement issues. For example, in a quasi-experimental study men and women in a minimum-security prison volunteered to take part in either a 10-day Vipassana (breath and body focused meditation) course or to receive treatment as usual (TAU; mental health and chemical dependency treatment/education). Those who took the course reduced their alcohol, marijuana, and crack cocaine use significantly at the three-month follow-up relative to those in the TAU group (Bowen et al., 2006). However, this study did not measure mindfulness directly and outcomes were confounded by self-selection of participants into treatment conditions. Thus, it is impossible to conclude whether the course increased mindfulness and whether changes in mindfulness were responsible for the observed reductions in substance use. In addition, meditation and relaxation training has led to decreases in alcohol use among college students (Marlatt \& Marques, 1977) but again measurement issues limit the interpretation of these findings as well. In the future, assessing mindfulness with a well validated measure pre and post treatment would allow for stronger research conclusions and would disentangle the impact of meditation vs. mindfulness on substance use. Mindfulness is characterized by awareness and attention to events and experiences throughout the day, and although it is often cultivated through meditation, it is not constrained by it. Thus mindfulness 
and meditation can not be treated as a singular,concept when researching and measuring mindfulness.

Sample size is an additional limitation of the extant research. In one pilot study, mindfulness meditation did not enhance the effectiveness of treatment for substance abuse at a drug treatment facility (Alterman et al., 2004). However, the sample size $(N=18)$ raises serious concerns about the ability to capture any meaningful changes. Likewise conclusions from a three-person study of acceptance and commitment therapy indicated reductions in marijuana use post-treatment but results cannot be generalized from this small sample (Twohig, 2007). In summary, the current research on mindfulness/meditation as a tool to reduce substance use and abuse is theoretically promising but conclusions regarding the effectiveness of these approaches are limited by methodological constraints.

While additional applied research on mindfulness-based treatments is needed, it is important to note that the basic relationship between mindfulness and substance use is still not well understood. There is only one published study examining the relationship between mindfulness and substance use. It indicates that college students higher in mindfulness consume more alcohol than those lower in mindfulness and smokers higher in mindfulness use more tobacco (Leigh, Bowen, \& Marlatt, 2005). Given the presumption that mindfulness is considered a means to reduce substance abuse, these findings are somewhat surprising. However, the above results could be sample specific; resulting from the use of a non-clinical sample for whom alcohol use is normative (Johnston, O'Malley, Bachman, \& Schulenberg, 2007). Alternatively, mindfulness may not be a reliable predictor of alcohol or other drug use, but may still 
be a means through by which to reduce it. One additional consideration is that the aforementioned research and other studies have often relied on unidimensional measures of mindfulness of unknown reliability and validity. A broader operational definition may be more informative to substance use research because mindfulness is an ambiguous and inconsistently defined construct for which the boundaries are not yet clearly agreed upon (Herndon, 2008). Broader measures with numerous facets allow for the examination of differential relationships between mindfulness factors and related constructs. For example, Baer et al. (2006) reported a wide range of correlations among specific psychological constructs (such as emotional intelligence, openness to experience, and neurtoticism, among others) and five factors of mindfulness (the five factors can be seen in Table 1). Research has yet to examine whether a multi-faceted measure would illuminate such differential relationships between substance use and mindfulness factors as well. Accordingly, further research is needed to test such a hypothesis.

\section{Measuring Mindfulness}

Uncovering the relationship between mindfulness and substance abuse, or any other health-related behavior, is only possible through proper definition, measurement, and validation of mindfulness as a psychological construct (Clark \& Watson, 1995). As previously noted there is disagreement in the field as to what elements are incorporated in mindfulness. For example there is debate as to whether mindfulness is defined as simply attention and awareness of the present moment, or if it also incorporates an orientation towards the present moment characterized by curiosity and acceptance (Bishop et al., 2004). Even the widely-disseminated mindfulness-based 
stress reduction program has been questioned due to the nonspecific definition and measurement of mindfulness implemented in its research trials (Bishop, 2002). A review of the published literature revealed that published measures of mindfulness vary widely in terms of content, scope, and psychometric validity. The measures range from 13 (Lau et al., 2006) to 39 items (Baer et al., 2006) and contain anywhere from one (Brown \& Ryan, 2003) to five factors (Baer et al., 2006). A summary of the each measure is presented here with regard to content, development, and psychometric properties. Unpublished measures of mindfulness such as the Cognitive and Affective Mindfulness Inventory (Feldman, Hayes, Kumar, \& Greeson, 2004, as cited in Baer et al., 2006) and the Mindfulness Questionnaire (Chadwick, Hember, Mead, Lilley, \& Dagnan, 2005, as cited in Baer et al., 2006) are largely omitted from discussion.

The Mindful Attention Awareness Scale. The Mindful Attention Awareness Scale (MAAS; Brown \& Ryan, 2003) is a purportedly unidimensional, 15-item measure of mindfulness. As the name suggests, item content focuses on attention and awareness of experience, both internal and external. The MAAS was developed and tested over a five-part study. Two versions of the measure, one focusing on state (intra-individual) and one emphasizing trait (inter-individual) variation, were created. The overall internal consistency coefficient for this measure was $\alpha=.87$. It was sensitive to between-subject differences and within-subject changes in mindfulness over time among adults with and without meditation experience, supporting its ability to detect state and trait elements of mindfulness in relevant populations (Brown \& Ryan, 2003). In addition, the MAAS has also been shown to discriminate across several relevant clinical dimensions such as attachment style (Cordon \& Finney, 2008) mood- 
disturbance, and stress (Carlson \& Brown, 2005). Measure development and validation, were carried out across numerous independent samples; however the underlying operational definition of mindfulness, which emphasizes attention and awareness only, is inconsistent with the underlying construct of mindfulness as defined by some researchers (Bishop et al., 2004; Roemer \& Orsillo, 2003). The omission of items that assess openness and receptiveness to experience may undermine the ability of the MAAS to accurately capture the construct of mindfulness in its entirety.

The Frieburg Mindfulness Inventory. The Frieburg Mindfulness Inventory (FMI; Buchheld, Grossman, \& Walach, 2001) is a 30-item, purportedly single factor measure. It was created from a qualitative literature review and includes items regarding the cognitive, affective, and behavioral components of mindfulness, including elements of awareness (i.e. "I sense my body, whether eating, cooking, cleaning, or talking") and acceptance (i.e. "I see my mistakes and difficulties without judging them"). An initial 38-item measure was subjected to testing among 115 adults at a meditation retreat and was further reduced to 30 -items. Validation of the scale took place among a heterogeneous population of adults with meditation experience, without meditation experience, and included patients receiving mental health services. Many items that were reliable and internally consistent when tested among the homogeneous meditation-experienced sample were not psychometrically sound among the mixed adult sample (Walach et al., 2006). The authors note that the meaning of some items may have been unclear to individuals without meditation experience. 
Although validation of the FMI took place across two studies (Buchheld et al., 2001; Walach et al., 2006) and the FMI successfully captured predicted increases in mindfulness following a meditation retreat (Buchheld et al., 2001), a lack of confirmatory factor analytic support and ambiguous item content overshadow these results. In conclusion, oversights in the development of this measure may limit its application.

The Toronto Mindfulness Scale. The Toronto Mindfulness Scale (TMS; Lau et al., 2006) is a 13-item, two-factor scale developed to reflect the two-part definition of mindfulness proposed by Bishop et al., (2004). Designed to assess retrospective reports of mindfulness related to a specific meditative or mindful event, this measure emphasizes the state characteristics of mindfulness, as opposed to most other measures which assess trait-level mindfulness. The two factors, Curiosity and Decentering, had an internal consistency alpha of .86 and .87 respectively (Lau et al., 2006). The Curiosity factor reflects awareness of the present moment (i.e. "I was curious about the nature of each experience as it arose") and the Decentering factor indicates one's ability to observe experience with some "distance and disidentification" (i.e. "I experienced my thoughts more as events in my mind than as a necessarily accurate reflection of the way things 'really' are."). Measure development took place among a mixed sample of adults $(N=390)$ with and without meditation experience.

A 2x2 MANOVA was carried out to discriminate mindfulness scores between individuals reporting varying types of meditation training and durations of experience. Practicing mindfulness meditation for more than one year was associated with higher scores on the Curiosity factor. Practicing Shambhala meditation for more than one 
year was associated with higher scores on the Decentering factor. The TMS Decentering factor also captured change in mindfulness pre and post-mindfulness training in a clinical sample as indicated by paired t-tests (Lau et al., 2006). The TMS is a promising measure; however it can only be used to assess state-level mindfulness in relation to discrete meditative events.

The Kentucky Inventory of Mindfulness. The Kentucky Inventory of Mindfulness (KIMS; Baer et al., 2004) is a 39-item, four-factor scale. The KIMS was developed with two goals in mind, a) to incorporate the purportedly multi-faceted nature of mindfulness into one measure and b) to assess mindfulness across both general and clinical populations by using item descriptions that are easily understood by the general population. Item content was influenced primarily by the behavioral descriptions of mindfulness provided by Linehan and colleagues (Linehan, 1987). Mindfulness was divided into a four-part operational definitions including (a) one's tendency to observe internal and external stimuli, (b) the ability to describe experiences, thoughts and feelings with words, (c) one's propensity to focus on activities with undivided attention, and (d) the ability to accept and allow experience, thoughts, and feelings to take place without judging and evaluating them. Psychometric testing took place on two undergraduate samples (Sample 1: $N=205$; Sample 2: $N=215$ ) and one clinical sample of patients with borderline personality disorder $(N=26)$.

In a small clinical sample the KIMS was able to successfully differentiate between "normal" students and individuals suffering from borderline personality disorder, a group known to score low in mindfulness (Baer et al., 2004). Further examination of 
this theoretically relevant measure and its factor structure is warranted. However, the measure was largely subsumed by another measure, presented next, which appears to be a more comprehensive and validated measure than its predecessor.

The Five-Facet Mindfulness Questionnaire. The Five-Facet Mindfulness Questionnaire (FFMQ; Baer et al., 2006) is a five-factor, 39-item measure of mindfulness, developed primarily to examine the facet structure of mindfulness. Five pre-existing measures of mindfulness were synthesized to create the FFMQ. They included three of the measures already discussed, the KIMS, the FMI, the MAAS, and two unpublished measures, the Cognitive Affective Mindfulness Scale (Feldman et al., 2004, as cited in Baer et al., 2006) and the Mindfulness Questionnaire (Chadwick et al., 2005, as cited in Baer et al., 2006). All five measures were administered to 613 undergraduates and an exploratory factor analysis was conducted on the combined dataset (102 items) revealing a five-factor, 39-item solution (see Table 1). A confirmatory factor analysis was conducted on an additional 268 participants and supported the five factor model among participants with meditation experience. However, among participants who were "meditation naïve" a four factor structure was determined to be a better fit. The four factor structure was created by omitting the "Observation of Experience" factor. This factor was differentially related to other factors in the model, and did load positively on an over-arching mindfulness factor when a hierarchical measure was tested. Subsequent analyses revealed that individuals without meditation were more likely to judge their experiences when attending to them, hence creating an unstable relationship between the "Observation of Experience" and "NonJudging" factors. (Baer et al., 2004; 2006).The factors and their 
coefficient alphas from this study were as follows: Non-Reactivity to Experience ( 7 items, $\alpha=.75$ ), Observation of Experience ( 8 items, $\alpha=.83$ ), Acting with Awareness (8 items, $\alpha=.87$ ), Describing one's Experience ( 8 items, $\alpha=.91$ ), and Non-Judging of Experience ( 8 items, $\alpha=.87$ ) (see Table 1 for sample items from each factor). Each factor contributed unique variability to the model as indicated by $\mathrm{R}^{2}$ values between .56 and .75 , coupled with relatively low inter-factor correlations. A regression analysis based on factors of the FFMQ was used to predict psychological functioning, measured using the Brief Symptom Inventory (Derogatis, 1992). Overall, the FFMQ accounted for $37 \%$ of the variance in psychological functioning and three of the factors (Acting with Awareness, Non-Judging of Experience, and Non-Reactivity to Experience) accounted for a significant portion of unique predictive ability, indicating incremental validity for these factors. In summary, the FFMQ is the most comprehensive measure of mindfulness developed to date for which thorough psychometric development and testing has been conducted.

\section{The Aims of the Current Study}

The aims of the current research were (a) to further validate a pre-existing measure of mindfulness, and (b) to examine the basic association between mindfulness and substance use among college students. In order to conduct the necessary validation and testing, a mindfulness measure was chosen from the measures presented. The FFMQ was chosen because it has undergone psychometric development most consistent with suggestions from experts in the field (Clark \& Watson, 1995), most clearly synthesizes numerous facets of mindfulness, incorporates a broad operational definition of mindfulness, and has been validated among a comparable subpopulation (i.e. college 
students). In addition, investigation of the FFMQ is timely because it is currently being used to evaluate an emerging mindfulness-based substance abuse treatment program (personal communication, Alan Marlatt 2007). Only one published study of the psychometric properties of the FFMQ is available in the literature (Baer et al., 2006), indicating the need for replication and further psychometric investigation.

Psychometric evaluation of the FFMQ was conducted using confirmatory factor analysis (CFA). This was followed by an examination of the associations between the FFMQ and other theoretically-related constructs. It was hypothesized that the FFMQ would have five distinct factors that would all load positively on a higherorder mindfulness factor. Past research by Baer et al., (2006) indicated a four-factor solution for the FFMQ among students without meditation experience, and a five factor solution among students with meditation experience. The current sample has varying (albeit low) levels of meditation experience, but was not large enough to subdivide by experience; thus a five-factor solution is predicted. Each factor was predicted to hold a positive correlation with constructs that incorporate elements of mindfulness, such as attentional control, objective awareness, and insight into thoughts and behaviors. Conversely, constructs which included elements incongruent with mindfulness such as acting impulsively, lacking awareness of long-term behavioral consequences, or disregulation of thoughts and emotions were predicted to hold a negative relationship with the factors of the FFMQ. The specific constructs and the predicted associations are presented in Table 2.

Following these validation procedures, the second aim of this proposal was to examine basic associations between mindfulness (as measured by the FFMQ) and 
alcohol use, alcohol-related consequences, and other drug use. Examinations of the relationships between the various factors of the FFMQ and substance use variables were carried out using structural equation modeling. All mindfulness factors were hypothesized to have a negative relationship with alcohol and drug use variables. 


\section{Methods}

\section{Sample Characteristics}

Data was collected from 322 participants taking part in an ongoing longitudinal trial. Six participants were dropped from analysis because they did not complete the FFMQ. The remaining participants $N=316)$ were included in all analyses. The sample was $56 \%(n=177)$ female, $92 \%(n=291)$ white, $3 \%(n=11)$ Hispanic, 3\% $(n=10)$ black, <1\% $(n=2)$ Asian, and 4\% $(n=13)$ "other" (categories are not mutually exclusive). The mean age was 22 years-old $(S D=.41)$. All students were either current or former students at the University of Rhode Island who entered the university as freshman in 2004. Eighty two percent $(n=259)$ of participants were still enrolled at URI full or part-time at the time of data-collection, $11 \%(n=35)$ were attending another college/university, and $7 \%(n=22)$ were no longer in school.

\section{Data Collection Procedures}

The data available for this proposal were gathered across four longitudinal time points beginning in the summer of 2004, and followed by a 10-month follow-up, a $22-$ month follow-up, and a 46-month follow-up. The data are part of a larger randomized clinical trial of two interventions designed to reduce alcohol use among college students. All data were gathered by telephone through the Survey Research Center at the University of Rhode Island. Participants provided their consent verbally over the phone at baseline (students under 18 years-old received parental consent) and again when the project aims were extended to include an additional follow-up at 46-months. Participants were compensated $\$ 25-\$ 50$ for their participation at each time point. The University of Rhode Island Institutional Review Board approved all study procedures. 


\section{Measures}

Measures from all four time points were utilized in the proposed analysis (baseline, 10-month, 22-month, and 46-month follow-ups). The measures are presented next in the following order: demographics, mindfulness, psychological constructs purported to be related to mindfulness, and measures of substance use and related negative consequences.

Demographics. Relevant demographic variables such as gender, race, and ethnicity were assessed at baseline.

Mindfulness. Mindfulness was measured using the Five-Facet Mindfulness Questionnaire (FFMQ; Baer et al., 2006). The FFMQ is a 39-item, five-factor measure that has been validated for use among college students in one previous study (Baer et al., 2006). The factors and their coefficient alphas for the current data were as follows: Non-Reactivity to Experience ( 7 items, $\alpha=.75$ ), Acting with Awareness ( 8 items, $\alpha=$ .87), Describing with Words ( 8 items, $\alpha=.87$ ), and Non-Judging of Experience ( 8 items, $\alpha=.88$ ), Observation of Experience ( 8 items, $\alpha=.84$ ). Respondents are asked to rate how true given statements are for themselves on a five-point Likert-type scale (i.e. $1=$ rarely true to $5=$ very often or always true). The FFMQ was administered at the 46-month follow-up along with a single item to assess past meditation experience (i.e. Do you have any experience with meditation?) Response options ranged from $1=$ none to $5=$ a lot.

Personality. Personality was measured using a revised version of the Eysenck Personality Questionnaire (EPQ-R; Eysenck, 1988). This measurement of personality among adults has a yes/no response format and has three major factors: extraversion, 
psychoticism, and neuroticism, as well items to assess social desirability. The short form used in this study has 57 -items. Median reliability across 44 studies for the EPQ$\mathrm{R}$ indicates three scales have adequate reliability (neuroticism $=.83$, extraversion $=$ .82 , and social desirability $=.77$ ) and one has low-moderate reliability (psychoticism $=$ .66; Caruso, Witkiewitz, Belcourt-Dittloff, \& Gottlieb, 2001) However, higher reliability on the psychoticism has been demonstrated among student samples (Caruso et al., 2001). Personality was assessed at the 22-month follow-up.

Impulsive sensation seeking. The Impulsive Sensation Seeking scale is part of the Zuckerman and Kuhlman's Personality Questionnaire (Zuckerman, Kuhlman, Joireman, Teta, \& Kraft, 1993). This scale assesses willingness to take risks and seek out novel experiences. It has demonstrated good internal consistency and has been shown to correlate strongly with substance abuse disorders (Zuckerman \& Cloninger, 1996). Response options are dichotomous (true/false). Impulsive sensation seeking was assessed at the 22-month follow-up $(\alpha=.80)$.

Need for cognition. The Need for Cognition Scale (NCS; Cacioppo, Petty, \& Kao, 1984) was developed to measure individual differences in motivation to engage in effortful, cognitive endeavors. The short 18-item form of the NCS has demonstrated high internal consistency across a number of studies (11 studies, average $\alpha=.89$ ) with factor analyses consistently replicating the unidimensional factor structure observed in the original study (Cacioppo \& Petty, 1982; Cacioppo, Petty, Feinstein, \& Jarvis, 1996). The five-point Likert-type response scale assesses the extent to which participants believe an item is characteristic of them (i.e., $1=$ extremely 
uncharacteristic to $5=$ extremely characteristic). This construct was measured at the 10-month follow-up $(\alpha=.80)$.

Consideration of future consequences. The Consideration of Future Consequences scale (Strathman, Gleicher, Boninger, \& Edwards, 1994) measures the degree to which individuals consider immediate versus distant consequences of attitudes and behavior. The 12-item single factor measure was developed across two separate studies and utilized seven samples of college students with an average coefficient alpha of .81 (Strathman et al., 1994). A Likert-type response scale assesses the extent to which a given item is characteristic of the participant (i.e. $1=$ extremely uncharacteristic to $5=$ extremely characteristic). This measure was administered at the 46-month follow-up $(\alpha=.77)$

Alcohol use. Alcohol use was measured using the Daily Drinking Questionnaire (DDQ; Collins, Parks, \& Marlatt, 1985). The DDQ records the number of drinks consumed on each day of a typical drinking week. Peak drinking over the past month was assessed using a single-item from the Quantity-Frequency Questionnaire (Dimeff, Baer, Kivlahan, \& Marlatt, 1999), which asks participants to indicate the number of drinks that they consumed on the occasion in which they drank the most in the past month. Heavy episodic drinking was measured with a single item asking participants how often they consumed five or more drinks (for males) or four or more drinks (for females) on one occasion over the past two weeks. This gender specific heavy episodic drinking measure is a standard in the field (Wechsler \& Nelson, 2008). All alcohol use variables utilized here were measured at the 46-month follow-up. 
Substance use. Substance use was measured with three individual items based on the assessment criteria used in the Monitoring the Future Study (Johnston et al., 2007). The items assess tobacco, marijuana, and illicit or non-medical use of all other drugs over the past year. The items are scored on a five-point Likert-type scale $(1=$ no use to $5=$ daily use). Substance use data were collected at the 46-month follow-up.

Alcohol-related consequences. Alcohol-related consequences were assessed with a 17-item version of the Young Adult Alcohol Problems Screening Test (YAAPST; Hurlbut \& Sher; 1992). The adapted YAAPST scale assessed past three-month frequency of alcohol problems for general consequences (e.g., hangovers, blackouts, driving while intoxicated) and problems presumably more unique to college students (e.g., missing class, engaging in high-risk sexual behaviors). A severity summary score was created by weighting each problem experienced by the number of times it occurred. Alcohol-related consequences were assessed at the 46-month follow-up ( $\alpha=$ $.88)$.

Data Analysis

Outlier adjustments. Variables or composite variables with a skew greater than two and kurtosis greater than four underwent data adjustment. All far outliers (cases more than three standard deviation outside the mean) were reduced to one value larger than the greatest non-far outlier (Fidell \& Tabachnick, 2003). Subsequent examination of distrubutions led to adjustments were for two scales: average number of drinks per week and average number of alcohol-related consequences.

Missing data. Confirmatory factor analyses were conducted using SAS proc CALIS, which uses listwise deletion to address missing data. However, this procedure 
was not applied because there were no missing data in the CFA models. Structural equation modeling was conducted using MPLUS (Muthén \& Muthén, 2006) which uses full information maximum likelihood for imputing missing values. Data had to be imputed for one participant who was missing data on one variable in the alcohol model.

Descriptive statistics. Descriptive statistics were examined for all variables of interest prior to investigating the primary study aims. The assumptions of the general linear model were examined with respect to central tendency (mean, median, mode), variance, skew, and kurtosis. Reliabilities (in terms of coefficient alpha) were examined for all relevant measures and are presented in the measures section.

Confirmatory factor analysis. Factor analysis is central to establishing construct validity (Clark \& Watson, 1995; Smith \& McCarthy, 1995) Exploratory and confirmatory approaches are recommended in succession to investigate and test hypothetical factor structures of a measure (Gorsuch, 1983). The prior exploratory factor analysis conducted by Baer et al. (2006) indicated a five-factor solution for the FFMQ. A follow-up CFA confirmed the five-factor solution and a hierarchical factor analysis indicated that all the factors were positively related to a single higher order mindfulness factor. However, among participants without meditation experience, a hierarchical model which omitted the 'Observe' factor, was a better fit (Baer et al., 2006).

Given this previous exploratory and confirmatory factor analyses on the FFMQ we elected to begin our analysis with a CFA. A five-factor model, four-factor model, single factor model, and a hierarchical model were tested and compared. Noar (2003) 
proposes that conducting a series of single factor, multi-factor and hierarchical models is appropriate when testing and developing a measure using CFA. The decision to test a four and five factor model was based on the differential findings regarding the four and five factor structure by Baer et al. (2006). Model fit was evaluated using multiple indices including the $\chi^{2}$ goodness-of-fit test. This test is a standard in the field however is not recommended as an isolated guide to model accuracy (Li-Tze \& Bentler, 1995) because it is sensitive to sample size and is likely to capture small and inconsequential differences between a model and the data. Adjunct fit indices include the comparative fit index (CFI) and the root mean square error of approximation (RMSEA; Marsh, Balla, \& Hau, 1996). For the CFI a score greater than .90 indicates acceptable model fit. For the RMSEA a .05 is considered a good fit, .08 a fair fit, and .10 a marginal fit (Kline, 2005). Model comparisons were made using $\chi^{2}$ difference tests.

A CFA requires a relatively large sample size to produce stable results, some recommend a sample size of 200-300 (Comrey \& Lee, 1992) and others have suggested that stability of results is affected most by component saturation (magnitude of loadings) and the number variables that load on each factor or component (Guadagnoli \& Velicer, 1988). The current sample size of 316 is considered adequate to conduct the proposed CFA. Item parcels were used in the study conducted by Baer et al., (2004) to reduce error variance and increase reliability of the factors (Little, Cunningham, Shahar, \& Widamon, 2002; MacCallum, Widaman, Zhang, \& \& Hong, 1999). Thus, this procedure was used again to allow for relevant comparison.

Correlation between the FFMQ and theoretically-related constructs. To determine the construct validity of a measure, predicted correlations with other theoretically- 
related constructs must be determined a priori and tested (Clark \& Watson, 1995; Nunnaly \& Bernstein, 1994). The choice of comparison constructs for the proposed research was driven by theory, past research, and data availability (see Table 2). The relationship between mindfulness and broad personality characteristics (as measured by the EPQ-R) were examined along the dimensions of neuroticism, extraversion, and psychoticism. It was predicted that all the factors of the FFMQ would be negatively associated with neuroticism because mindfulness emphasizes awareness of internal states without judging thoughts as good or bad/right or wrong. This orientation of acceptance is theoretically incongruent with neurotic thought processes, particularly obsession and rumination. Similarly, psychoticism is characterized by poor reality testing, poor insight, and emotional dysregulation. Thus, psychoticism was predicted to hold a negative relationship with all the factors of the FFMQ because of their overarching emphasis on awareness, insight, and accurate identification of internal and external experience. Only one factor of the FFMQ was predicted to have a positive association with extraversion. The 'Describe' factor emphasizes the ability to put one's internal experience into words. Because this factor involves interpersonal communication it is presumed to be higher among more extroverted individuals.

More narrow-band measures of personality were also examined including need for cognition, impulsive sensation seeking, and orientation towards future consequences of behavior. Need for cognition, which refers to an individual's propensity to engage in deep thinking and enjoy cognitive oriented activities, was predicted to hold a positive relationship with mindfulness because of the emphasis on awareness of thoughts necessary for cognitive endeavors. A positive relationship was 
found between need for cognition and mindfulness in past research (Brown \& Ryan, 2003). In this study impulsivity and sensation seeking were combined in one scale which measures an individual's propensity to seek out novel experiences and take risks. This construct is incongruent with the ability to observe thoughts and feelings without reacting to them and thus a negative relationship with mindfulness was predicted. In terms of orientation towards future consequences of behavior, higher scores on this scale indicate a propensity to consider the long term consequences of attitudes and behaviors. Mindfulness is incongruent with short-sighted actions and attitudes and thus a positive relationship was predicted. Lastly, a positive correlation was predicted between meditation experience and all factors of mindfulness. Factor level correlations were examined to indicate whether the various constructs are differentially related to the distinct facets of mindfulness. Alpha inflation is a concern when examining such a large number of correlations, thus a Bonferroni adjustment was applied.

Structural equation models. In an attempt to inform future research and more fully understand how mindfulness relates to health and behavior, the basic associations between mindfulness and substance use were examined using structural equation modeling, a comprehensive statistical approach used for testing hypotheses about relations among observed and latent variables (Hoyle, 1995). It is preferable over other multivariate procedures such as multiple regression or canonical correlation because the relationship between numerous continuous and categorical variables can be examined concurrently, direct and indirect relationships can be modeled, several 
measures of each construct can be included in one model, and measurement error is taken into account (Raykov \& Marcoulides, 2000).

It is crucial to ensure that latent variables included in the structural equation models are accurately created from the observed variables. The CFA for the FFMQ was undertaken to assure the accuracy of this respective set of latent variables. Daily drinking, heavy episodic drinking, and peak drinking were all hypothesized to create one latent alcohol use factor. Past research has indicated that measures of alcohol consumption such as these are highly intercorrelated (Weitzman \& Nelson, 2004; Wood, Read, Palfai, \& Stevenson, 2001). To ensure this is the case, the intercorrelation of the alcohol use variables and their loadings on the latent alcohol use factor were examined. In addition the intercorrelation of drug use variables were considered before the model was finalized and tested. Model fit was assessed using the same fit indices and cut off scores discussed with respect to the CFA model.

Finally, the directionality and magnitude of the relationship between the FFMQ and substance use variables were examined. Although these models were largely exploratory, the value of the paths between each factor and the endogenous variables could be tentatively estimated based on past research. Accordingly, all factors of the FFMQ were predicted to hold negative correlations with the alcohol and drug use variables. As mentioned past research has indicated that midnfulness and alcohol use were positively related (Leigh et al., 2005). However, this research was used extreme group comparisons (binge drinkers vs. abstainers) and used a unidmensional measure of mindfulness that may have obscured findings. This prediction was further based on past findings indicating consistent negative 
correlations between the FFMQ factors and psychological and emotional difficulties (Baer et al., 2006) known to be associated with alcohol and drug abuse (Grekin, Sher, \& Wood, 2006; Zucker, Donovan, Masten, Mattson, \& Moss, 2008). However, the magnitude of these negative correlations was predicted to vary across factors. Alcohol and drug use are positively correlated with some aspects of mindfulness such as openness to experience (Eisenman, Grossman, \& Goldstein, 1980; Jackson, Sher, \& Schulenberg, 2008; Sher, Wood, Crews, \& Vandiver, 1995). Therefore the three FFMQ factors that were positively related to openness to experience in past research (Baer et al., 2004; 2006) were predicted to have weaker negative relationships with alcohol and drug use. These include Observation of Experience, Describing with words, and Non-Reactivity to experience. Overall the strongest negative correlation was predicted between the factor Non-Judging of Experience and substance use. This factor held the strongest negative relationship with measures of psychological and emotional difficulty and had a near-zero correlation with openness to experience (Baer et al., 2006). 


\section{Results}

\section{Descriptive Statistics}

In terms of alcohol use $95 \%(n=291)$ of participants reported consuming alcohol in the past year. Among current drinkers, the mean number of drinks consumed in a typical week was $12.1(S D=10.7)$. The average number of 'peak' drinks (maximum number consumed on any one occasion in the past month) was 5.6 $(S D=2.9)$ for females and $8.9(S D=5.2)$ for males. The average number of heavy drinking episodes in the past two weeks was $2.3(S D=2.6)$, and the average number of alcohol-related consequences experienced in the past three months was $8.0(S D=$ 8.9). The most common alcohol-related problem was hangovers, experienced by $61 \%$ ( $n=193$ ) of the sample. Second most common were blackouts, experienced by $50 \%$ ( $n$ $=159)$ of the sample. Additionally, $16 \%(n=52)$ reported drunk driving, and $13 \%$ ( $n$ $=40$ ) were involved in sexual situations they later regretted.

In terms of drug use, the majority of the sample had not smoked cigarettes $(71 \%, n=223)$, used marijuana $(63 \%, n=200)$, or abused other drugs $(94 \%, n=296)$ in the past year. Of those who reported cigarette use, daily use was reported by $8 \%$ ( $n$ $=26)$, weekly use was reported by $6 \%(n=19)$, monthly use by $4 \%(n=14)$, and less than monthly use by $11 \%(n=34)$. In terms of marijuana use, $5 \%(n=17)$ of the sample reported daily use, $7 \%(n=22)$ reported weekly use, $11 \%(n=34)$ reported monthly use, and $14 \%$ ( $n=43$ ) reported less than monthly use. Daily illicit drug use was reported by only one subject and only one subject reported weekly use. Two percent $(n=6)$ of the sample reported monthly use of illicit drugs, and $4 \%(n=12)$ reported less than monthly use. All drug use variables were significantly correlated ( $p$ 
$<.001) ; r=.38$ for smoking and marijuana use, $r=.21$ for smoking and other drug use, and $r=.40$ for marijuana and other drug use.

In terms of meditation experience, $55 \%(n=173)$ of participants reported having no experience with meditation, $32 \%(n=100)$ reported "a little", $10 \%(n=31)$ reported "a medium amount", $2 \%(n=5)$ reported "quite a bit"; and $2 \%(n=7)$ reported "a lot." Thus meditation experience in this sample was relatively low (87\% of the sample had little to no experience).

Baseline equivalence. Chi-square tests revealed that the sample was representative of the overall URI population in terms of gender, race, and ethnicity. This study utilized data from the 46 month follow-up of an ongoing longitudinal trial. There were no significant baseline differences between participants who did and did not complete the 46-month follow-up in regards to gender, race, ethnicity, drinking status (abstainer vs. drinker), average number of drinks consumed per week, heavy episodic drinking, or alcohol-related consequences.

Confirmatory Factor Analysis

All CFAs were conducted using the data collected from the 316 participants who completed all 39 items of the FFMQ. Data were analyzed using SAS system's CALIS procedure using maximum likelihood estimation. All preliminary models were nested to allow for comparisons using $\chi^{2}$ difference tests, and all models used item parcels as manifest variables. To create item parcels two or three items were randomly selected within each of the factors. The average of the items was taken to create a composite score. These procedures followed those used by Baer et al. (2006). To conduct a CFA at least one parameter must be fixed for each latent construct (Kline, 
2005). In this research, the variance of each factor was fixed at 1 and all factor loadings were free. In addition, all factors were allowed to intercorrelate, except where otherwise indicated.

Three different models were compared to determine the appropriate factor structure for the data including a five factor model, a four factor model, and a single factor model. As mentioned, Noar (2003) suggested testing a series of CFA models when determining measurement structure and Baer et al. (2006) found differential factor structures among participants with varying levels of meditation experience. Thus model comparisons were needed to determine the most appropriate factor structure for the current data. Nested models were created by restricting specific parameters of the five-factor model (Bollen, 1989). The nested four factor model was created by setting the covariance paths between the 'Observe' factor and all other factors to 0 . This model was tested because the 'Observe' factor was misspecified among "meditation naïve" college student in research by Baer et al. (2006). The single factor model was created by setting the covariances of all the factors to 1 , creating one unidimensional measure. Fit indices for all models are presented in Table 3. The results of the five factor model indicated an acceptable fit: $\chi^{2}(80, N=316)=335.84, \mathrm{p}$ $<.001, \mathrm{CFI}=.90, \mathrm{RMSEA}=.10$ (see Figure 1). The fit of the four factor model was marginal: $\chi^{2}(84, \mathrm{~N}=316)=452.25, \mathrm{p}<.001, \mathrm{CFI}=.85, \mathrm{RMSEA}=.12$ and the single factor model fit the data poorly: $\chi^{2}(90, N=316)=1690.95, \mathrm{p}<.001, \mathrm{CFI}=.35$, RMSEA $=.24$

Chi-square difference tests were used to determine the model of best fit. These comparisons supported selection of the five factor model. The difference between the 
chi square values for the five and four factor model was 116.41 with a change in degrees of freedom of four. This difference was significant at the $p<.001$ level. The single factor model was not compared with the other models because the fit indices clearly indicate that this was a poor fitting model.

All factor loadings in the five factor model were significant at the $\mathrm{p}<.001$ level. Their standardized factor loadings ranged from .50 to $.96\left(\mathrm{R}^{2}=.25\right.$ to .81 ; see Figure 1). However, a number of other model results indicated problems with model fit. The average standardized residual (1.8) was large (Raykov \& Marcoulides, 2000) and the Lagrange and Wald tests (for adding or dropping paths) suggested areas of model misspecification. One indicator, Parcel 7, was responsible for nine out of ten of the largest standardized residuals, which ranged from an absolute value of 5.2 to 7.2. To improve model fit, the Lagrange multiplier test suggested adding paths from Parcel 7 to other mindfulness factors. Adding the recommended paths would have enhanced model fit substantially but would have obscured interpretation of the model. Therefore, Parcel 7 was removed.

Conducting the CFA without Parcel 7 improved model fit: $\chi^{2}(67, N=316)=$ $195.19, \mathrm{p}<.001, \mathrm{CFI}=.94, \mathrm{RMSEA}=.08$. The average standardized residual was reduced to 1.4 , which was an improvement from 1.8 but still relatively large. Standardized factor loadings are presented in Figure 2. All loadings were significant at the $\mathrm{p}<.001$ level. The $\mathrm{R}^{2}$ values for each factor ranged from .25 to .81 which reflect large multivariate effect sizes (Cohen, 1992). These findings generally support the factor structure proposed by Baer et al., (2006) with one major modification (the removal of Parcel 7). In addition, the large amount of residual variance that remains in 
the model is a concern and indicates areas of potential model misspecification that should be investigated in future research.

To examine the hypothesis that these factors are part of an overarching mindfulness construct, a hierarchical model was tested. All factors were used as indicators of one higher order factor (hypothesized to represent mindfulness). Model fit was acceptable: $\chi^{2}(72, N=316)=261.52, \mathrm{p}<.001, \mathrm{CFI}=.92, \mathrm{RMSEA}=.09$. All factor loadings in the hierarchical model were significant $(p<.001)$ and standardized loadings of the five factors on the higher order mindfulness factor were .59 for the 'Non-Reactivity' factor, -.26 for the 'Act with Awareness' factor, .46 for the 'Describe' factor, -.43 for the 'Non-Judging' factor, and .88 for the 'Observe' factor (see Figure 3). A $\chi^{2}$ difference test comparing the hierarchical and nonhierarchical five factor model favored the nonhierarchical model $(\mathrm{p}<.001)$. This indicates that the hierarchical model may not be appropriate for this data. This conclusion is further supported by the values of the factor loadings. The 'Act with Awareness' and 'NonJudging' factors loaded negatively on the mindfulness factor indicating these factors are inversely related to mindfulness as it is modeled here. These findings do not support the study hypothesis that all factors are part of an overarching mindfulness construct. For this reason, all factors were treated separately in subsequent analyses and the five-factor model with Parcel 7 removed was chosen as the final model for the purposes of this study.

\section{Correlations Between Mindfulness Factors and Other Constructs}

The correlations between the factors of the FFMQ and the other constructs of interest are presented in Table 4. Due to the large number of correlations examined a 
Bonferroni adjustment $(\mathrm{p}<.05 / 31=.0016)$ was applied. Thus, only correlations significant at the $\mathrm{p}<.0016$ level are indicated as significant. Overall the pattern of significant relationships shows inconsistent support for the study hypotheses. Predicted positive correlations between the 'Describe' factor and meditation, future consequences, and need for cognition were supported. This indicates that the ability to describe and label thoughts and feelings was higher among participants with meditation experience. It was also higher among those with a propensity to consider future consequences of behaviors and engage in cognitive endeavors. The "Describe' factor was not related to extraversion as indicated by the near zero relationship between these variables, suggesting that the ability to describe internal states is not a function of being more social or outgoing. The 'Observe' factor was positively related to meditation and need for cognition, indicating that those who were more aware of their physical sensations and perceptions in the present moment were more likely to have meditation experience and more likely to engage in and enjoy cognitive pursuits. The 'Non-Reactivity' factor was positively related to awareness of future consequences. Those who were able to observe their thoughts and feeling without reacting were also more likely to consider the long-term consequences of their attitudes and actions. The 'Act with Awareness' and 'Non-Judging' factor did not hold any predicted positive relationships with the constructs of interest.

Predicted negative correlations were observed between the 'Act with Awareness' factor, neuroticism, and impulsive sensation seeking. Those who were more aware of their actions in the present moment were less likely to engage in impulsive risk taking behavior, and were also less prone to engage in ruminative 
thought processes. The 'Non-Judging' factor, which emphasizes the acceptance of thoughts and feeling without labeling them as good or bad, was also negatively correlated with neuroticism. However, all other predictive negative relationships were insignificant, or significant in the direction counter to prediction. For example, the 'Observe' factor was significantly positively correlated with neuroticism. In general, these findings provide mixed support for the study hypotheses.

\section{Structural Equation Modeling}

The proposed structural equation models of mindfulness and substance use are presented in Figure 4 and Figure 5. The first model (Figure 4) depicts the relationship between mindfulness and alcohol use and problems. The second model (Figure 5) depicts the relationship between mindfulness and drug use (excluding alcohol). Both models incorporate the five factors of the FFMQ as exogenous (or independent) variables (labeled with their factor names). Directional paths connect them to their respective endogenous (or dependent) variables.

As noted, the data utilized for the proposed analyses were gathered for an ongoing randomized clinical trial crossing two brief interventions in a $2 \times 2$ factorial design. The interventions used in the study, a brief motivational intervention, and a parent based intervention, have been shown to reduce alcohol use and negative consequences among college students (Larimer \& Cronce, 2002; 2007; Turrisi, Jaccard, Taki, Dunnam, \& Grimes, 2001). Thus, these potential intervention effects were statistically controlled for in analyses involving substance use outcome measures. Intervention conditions (dummy coded, $1,-1$ ) were incorporated into both models as manifest variables (not shown in figures). The covariance with all other 
endogenous (alcohol use) variables were estimated to control for intervention effect. This study also included participants who abstained from alcohol. Those who did not report alcohol use in the past year $(n=25)$ were given scores of 0 on all alcoholrelated variables. All latent variable modeling was conducted using MPLUS with maximum likelihood estimation. Only one participant was missing data (on heavy episodic drinking) in the alcohol model.

Alcohol model. Direct paths from the five factors of the FFMQ to alcohol use and alcohol-related consequences were included in the model as seen in Figure 4. Alcohol use was included as a latent variable and was comprised of weekly drinking, peak drinking, and heavy episodic drinking. Alcohol-related consequences were combined into one scale which was included as a manifest variable. A one way path from alcohol use and alcohol-related consequences was included to account for the known association between these variables.

Model fit was good: $\chi^{2}(148, \mathrm{~N}=316)=282.219 ; \mathrm{p}<.001, \mathrm{CFI}=.95, \mathrm{RMSEA}=.05$. Figure 4 displays all standardized path coefficients. It can be seen that alcohol use was significantly and negatively related to two of the five factors of the FFMQ, the 'Describe' factor $(\beta=-.18, p<.05)$, and the 'Act with Awareness' factor $(\beta=-.17, p$ $<.05)$. The $\mathrm{R}^{2}$ values indicate that these two factors accounted for approximately $3.2 \%$ and $2.9 \%$ of the variance in alcohol use respectively. After controlling for robust associations between alcohol use and consequences, the 'Non-Reactivity,' 'Act with Awareness,' and 'Non-Judging' factors demonstrated marginally significant negative associations with alcohol-related consequences (all $p$ 's $<.10$ ). Together, these findings 
suggest more mindful individuals consume less alcohol and may experience modestly reduced levels of alcohol-related consequences independent of alcohol use.

Drug model. Direct paths from the five factors of the FFMQ to drug use (smoking, marijuana, and other illicit drug use) were included in the model (see Figure 5). Drug use variables were modeled as separate manifest variables because of their low correlations with one another ( $r$ 's $=.21$ to .40$)$. Base rates for drug use in this sample were very low. In an attempt to create a more appropriate model, the drug use variables were turned into dichotomous variables (use/non-use). However, the drug model would not converge. 


\section{Discussion}

This study was designed to inform the burgeoning use of mindfulness in thirdwave cognitive behavioral interventions (Hayes, 2004) through further validation of the FFMQ and examination of the relationship between mindfulness and alcohol and drug use. The FFMQ was predicted to contain five distinct factors that all loaded positively on an overarching mindfulness factor. The factors of the FFMQ were also hypothesized to hold positive and negative correlations with predetermined personality and psychological constructs. Lastly, the factors of the FFMQ were predicted to be negatively related to alcohol and drug use variables. The results of correlational analysis, CFAs, and latent variable analyses are discussed next in the context of the larger literature.

Interpretation of Results

Confirmatory factor analysis. Results of the CFA clearly indicated that the FFMQ contained five distinct factors. This determination was made through the interpretation of standard fit indices and $\chi^{2}$ difference tests comparing a five, four, and single factor model. The factor structure determined by this research supports the findings originally published by Baer et al. (2006). However, results of a hierarchical CFA indicated that two of the five factors of the FFMQ were negatively related to a higher order mindfulness factor. Theoretically, more mindful individuals should have higher scores on all factors. These findings indicate that the FFMQ may not be a valid measure of mindfulness as a unified construct. These findings also suggest that the factors of this scale should be considered separately in subsequent research. 
Past research conducted among college students also indicated inconsistency in the relationships between the factors of the FFMQ and an overarching mindfulness construct. Across two studies the 'Observe' and 'Non-Judging' factor were found to hold a significant negative relationship among individuals without meditation experience (Baer et al., 2004; 2006). In addition, the 'Observe' factor was unrelated to a higher order mindfulness factor (Baer et al., 2006). After investigating the possible explanations for these results the authors concluded that individuals without meditation experience tended to judge experiences when attending to them. Only when analyses were conducted among individuals with meditation experience was a positive relationship between observing and non-judging found (Baer et al., 2006). Considering our study consisted primarily of individuals who did not have meditation experience it is not surprising that we also found a negative relationship between the 'Observe' factor and 'Non-Judging' factor $(r=-.35)$. Thus, similar to past research, participants in this study who attended to experiences also tended to judge them. This negative relationship may also explain why the 'Non-Judging' factor loaded negatively on the higher order mindfulness factor.

A review of the standardized residuals, LaGrange test, and Wald test revealed that Parcel 7 of the 'Describe' factor was responsible for a large proportion of model misspecification. For this reason Parcel 7 was removed from the model and subsequently model fit improved. Parcel 7 was made up of three items.

1. I have trouble thinking of the right words to express how I feel about things.

2. It's hard for me to find the words to describe what I am feeling. 
3. When I have a sensation in my body, it's difficult for me to describe it because I can't find the right words.

Because there were no obvious theoretical differences between these items and other items in the 'Describe' factor, alternative explanations for model misspecification were examined. Through random selection Parcel 7 contained all of the reverse-scored items in the 'Describe' factor. In addition, the Lagrange tests suggested adding paths from Parcel 7 to the 'Act with Awareness' factor and the 'Non-Judging' factor. Both of these factors contain exclusively reverse-scored items. This suggested that Parcel 7 was related to other factors due to similarity in scoring procedures rather conceptual overlap.

Additional evidence for the role of measurement error in this data was revealed when examining the hierarchical CFA results. The two factors, "Act with Awareness" and "Non-Judging" which loaded negatively on the higher order mindfulness factor consisted of exclusively reverse-scored items while those that loaded positively did not. Without a clear conceptual reason for these findings a number of explanations can be posited. It is possible that by coincidence all reverse-scored items were conceptually different from non-reversed items. Alternatively, systematic error could have been introduced during data collection through survey administration error, misunderstanding by the participants, participant fatigue, or poorly written items.

Correlations. The predicted relationships between the factors of mindfulness and other constructs of interest were not consistently supported. Specifically, nine of the correlations were significant in the predicted direction, one was significant in the opposite direction, and 21 were not significant. A very conservative Bonferroni 
adjustment may account for the small number of significant correlations. Positive correlations were found between orientation toward future consequences and the 'Act with Awareness' and 'Describe' factors. This suggests that awareness of the present moment does not preclude the ability to foresee the long-term outcomes of behaviors. One could theorize that because mindfulness emphasizes awareness of the present moment it would be associated with short-sighted actions and attitudes. The findings reported here suggest that this is not the case. In addition, individuals who were more aware of their actions in the present moment were less likely to report impulsive sensation seeking behavior. These findings further indicate that individuals higher in mindfulness are more likely to behave with foresight and consider the outcomes of their actions.

Need for cognition was higher among individuals who reported an ability to describe their internal states and observe their experiences. These finding suggest that more mindful individuals are more likely to be intellectually curious and engage actively in cognitive tasks. However, additional research should determine whether this relationship is congruent with mindfulness (i.e. indicates increased curiosity and thoughtfulness regarding the self and environment) or whether it is incongruent (i.e. indicates a propensity to intellectualize thoughts and feelings). Finally, meditation experience was related to two factors of mindfulness including the 'Observe' factor, which is considered to be the most central element of mindfulness.

Many of the predicted relationships between mindfulness and the impulsive sensation seeking scale were not supported. This scale confounds two constructs that may be differentially related to mindfulness. Past research has indicated that sensation 
seeking and openness to experience are higher among more mindful individuals (Brown \& Ryan, 2003) while impulsivity is believed to be negatively related to mindfulness. Non-significant correlations between other factors of the FFMQ and impulsive sensation seeking may be attributed to the combination of these constructs into one scale. Future research should examine these constructs separately.

Counter to prediction, the 'Observe' factor was positively related to neuroticism. The 'Observe' factor measures a person's tendency to notice thoughts, feelings, and sensations. Many people with anxiety disorders, particularly panic disorder, report sensitivity to affective and physical states, sometimes referred to as hypervigilance (Eysenck, 1992; Reiss, Peterson, Gursky, \& McNally, 1986; Tull, Rodman, \& Roemer, 2008). The positive relationship between the 'Observe' factor and neuroticism suggest that this factor may actually measure neurotic awareness of internal states in some individuals. On the other hand 'Non-Judging' emphasizes the ability to objectively observe the self without passing judgment on the quality of thoughts and feelings, and this factor was negatively related to neuroticism. Thus, 'Non-Judging' may be a better predictor of objective awareness of internal states. These findings are consistent with suggestions that mindfulness is defined, in part, by one's quality of awareness (Bishop, 2004). Assessing the quality of awareness may be especially important when assessing mindfulness among individuals without meditation training.

Structural equation modeling. Results of the structural equation model examining the relationship between mindfulness, alcohol use, and alcohol-related consequences indicated significant negative relationships between alcohol use and the 'Act with 
Awareness' and 'Describe' factors. Individuals who were more aware of their actions and more able to put their thoughts and feeling into words were also lighter drinkers. Several factors including 'Act with Awareness,' 'Non-Reactivity,' and 'Non-Judging' held marginally significant negative relationships with alcohol-related consequences even after the robust relationship with alcohol use was controlled for. These results suggest that independent of alcohol use, more mindful individuals were less likely to experience alcohol-related consequences. A possible direction for future research would be exploring whether mindfulness mediates the relationship between alcohol use and consequences.

Interpreting these findings is difficult because the current research represents the first known examination of the relationship between alcohol use and specific facets of mindfulness. However, it is not surprising that those individuals who were more aware of their thoughts and less likely to react to or judge them were also less likely to drink heavily and engage in alcohol-related risk taking. Increased alertness and 'reduced readiness for action' are mechanisms of mindfulness believed to reduce substance abuse (Witkiewtiz and Marlatt, 2005) and the negative factor loadings reported here support this hypothesis. These findings are also consistent with past research indicating that impulsivity or 'mindless' behavior is positively related to hazardous drinking among college students (MacKillop, Mattson, MacKillop, Castelda, \& Donovick, 2007). Observing experience without reaction may be a marker of behavioral restraint that can be increased through mindfulness training. This hypothesis should be assessed in future substance abuse research. Our findings also suggest that individuals who are less-judgmental of their thoughts and feelings were 
less likely to experience alcohol-related harm. Linehan (1991) has indicated that reducing judgment of thoughts and feelings enhances psychological well-being. Training in mindfulness skills such as objective observation of thoughts and feelings can help individuals suffering from substance dependence disorders, according to one past study (Harned et al., 2008). Our findings also suggest that the ability to verbalize thoughts and feelings is negatively related to alcohol use and consequences. It is unclear whether this relationship is a function of an increased ability to recognize feelings or if verbalizing them is uniquely important. The ability to identify, but not verbalize, thoughts and feelings was found to mediate reductions in alcohol use following a mindfulness retreat in one study (Bowen, Witkiewitz, Dillworth, \& Marlatt, 2007).

It is interesting to note that there were no positive relationships between any of the factors of mindfulness and alcohol use. Past research has indicated a positive association between these constructs (Leigh et al., 2005). Comparing results from these two studies is difficult because different measures and data analysis procedures were used. Arguably, the current research was a more robust examination of the relationship between mindfulness and alcohol use for several reasons. This study used more sophisticated data modeling procedures (i.e. structural equation modeling), included a broad and multi-faceted measure of mindfulness, and modeled alcohol use as a continuous latent construct. Leigh et al. (2005) used a unidimensional measure of mindfulness, defined alcohol use as dichotomous variable (binge drinkers/nondrinkers), and used a t-test to examine differences between binge drinkers and nondrinkers. Leigh and colleagues combined all the items of their mindfulness 
questionnaire into one scale despite a principal components analysis suggesting a three-factor structure. Due to these differences the results of the current research may be a more accurate reflection of the relationship between alcohol use and mindfulness.

\section{Limitations}

A number of limitations should be considered when interpreting these findings. This sample contained exclusively current or former university students. University students are more likely to be affluent and academically oriented than their noncollege attending peers. In addition, this sample contained few racial or ethnic minorities, and most students were raised in the Northeastern United States. These distinct background characteristics may have influenced study results and therefore limit the ability to generalize findings. The use of item parcels was both a strength and limitation of this study. Item parcels create more stable indicators of latent variables and more closely approximate continuous measurement (Little et al., 2002). However, parceling made it impossible to determine which of the items (or which combination of items) in Parcel 7 were responsible for model misspecification. This is a limitation of this research and of item parceling in general. Post hoc model adjustments, like the removal of Parcel 7, should be interpreted cautiously. Replication in future research is needed to determine whether the items in this parcel were actually complex and multifactorial or whether the findings were due to chance.

Certain constructs of interest such as, need for cognition, personality, and impulsive sensation seeking, were measured at time points preceding the collection of mindfulness data. In this longitudinal trial, personality was measured at the 22-month follow-up, two years prior to the measurement of mindfulness. Research indicates that 
a time interval of two years is one in which substantial personality change is unlikely to take place (Bazana \& Stelmack, 2004). Test-retest reliability of personality inventories indicate that reliability does decrease as test intervals increase but the findings are less pronounced among adults (Schuerger, Zarrella, \& Hotz, 1989). It is recognized that the discontinuity of assessment in this proposal is not ideal, but is minimized by the relative stability of the constructs of interest. Thus, the use of these constructs in assessing construct validity of the FFMQ is considered informative and meaningful.

Finally, the role of measurement artifact in these data is a serious issue. Further investigation of measurement error is central to determining the validity of the FFMQ. Retrospective investigation of error will be conducted by examining existing data as well as additional data currently being collected. This ongoing data collection provides an opportunity to observe surveys being administered to detect potential errors in administration. It is possible that the reverse-scored items are being presented incorrectly, or that respondents are confused by the numerical scale that is used. In addition, the FFMQ was administered to participants near the end of a lengthy assessment battery, thus fatigue may have introduced bias in responding.

\section{Future Directions}

The popularity and empirical support for third-wave cognitive behavioral therapies such as Dialectical Behavior Therapy (Linehan, 1987) and Acceptance and Commitment Therapy (Hayes, 2004) underscores the importance of developing reliable and valid measures of mindfulness. So called third wave therapies, incorporate mindfulness in both their philosophy and application through training in meditation or 
mindfulness skills. The FFMQ would be a useful instrument by which to measure treatment outcomes from such therapeutic approaches. It is the broadest measure of mindfulness developed to date has undergone psychometric development and testing consistent with recommendations by experts in the field (Clark \& Watson, 1995). Despite study findings indicating negative relationships among some of the factors it remains a useful and promising measure. However, additional research is needed to determine whether the FFMQ measures mindfulness as an overarching construct or if, perhaps, mindfulness is a multi-faceted construct that is better explained by the interplay between various factors.

In terms of causation, the results of the structural equation modeling procedures were fundamentally based on the correlations between constructs and do not indicate any causal relationship between variables. Despite the negative relationship between some aspects of mindfulness and alcohol use, we can not infer with certainty that mindfulness can be manipulated to reduce alcohol use. Ultimately, research on mindfulness-based addiction treatments should measure mindfulness pre and post intervention to determine whether increases in mindfulness can be linked to decreases in alcohol or drug use through mediation analyses (MacKinnon, 2008). Unfortunately, many mindfulness-based treatment outcome studies in the past have omitted such measures altogether.

Validation of the FFMQ and investigation of its relationship with alcohol use is timely because the framework of mindfulness-based treatments is being expanded to incorporate alcohol and drug abuse treatment. Witkiewitz and colleagues (2005) describe a mindfulness-based addiction treatment that aims to increase awareness, 
acceptance, and non-reactivity to experience, particularly with regards to thoughts and physical sensations associated with drug craving. The results reported here support this treatment model. However, additional research on the relationship between mindfulness and alcohol use/abuse is needed to inform burgeoning mindfulness-based treatments. In particular research such as this should be replicated among an alcohol dependent clinical population. Participants in this study were not selected on the basis of any alcohol use criteria. In fact, some subjects did not drink alcohol at all. Thus results may differ dramatically among an alcohol abusing/dependent population. Future application of this measure among clinical populations may reveal more robust negative relationships between the factors of mindfulness and alcohol-related outcomes. Ultimately, continuing research is the only way to approximate the true relationship between mindfulness and substance abuse. 
Table 1.

Sample Items from FFMQ Factors

Factor

Sample Items

Non-reactivity to

Experience

I perceive my feelings and emotions without having to react to them.

In difficult situations I can pause without immediately reacting.

Usually when I have distressing thoughts or images, I just notice them and let them go.

Acting with

Awareness

I find it difficult to stay focused on what's happening in the present (reverse scored).

I rush through activities without being really attentive to them (reverse scored).

I am easily distracted (reverse scored).

Describing with Words

I'm good at finding words to describe my feelings.

I can usually describe how I feel at the moment in considerable detail.

When I have sensations in my body, it's hard for me to describe it because I can't find the right words (reverse scored).

Non-judging of Experience

I criticize myself for having irrational or inappropriate emotions (reverse scored).

I tell myself I shouldn't be feeling the way I am feeling (reverse scored).

I believe some of my thoughts are abnormal or bad and I shouldn't think that way (reverse scored).

Observation of I pay attention to how my emotions affect my thoughts and Experience behavior.

I notice how foods and drinks affect my thoughts, bodily sensations, and emotions.

When I'm walking I deliberately notice the sensations of my body moving. 


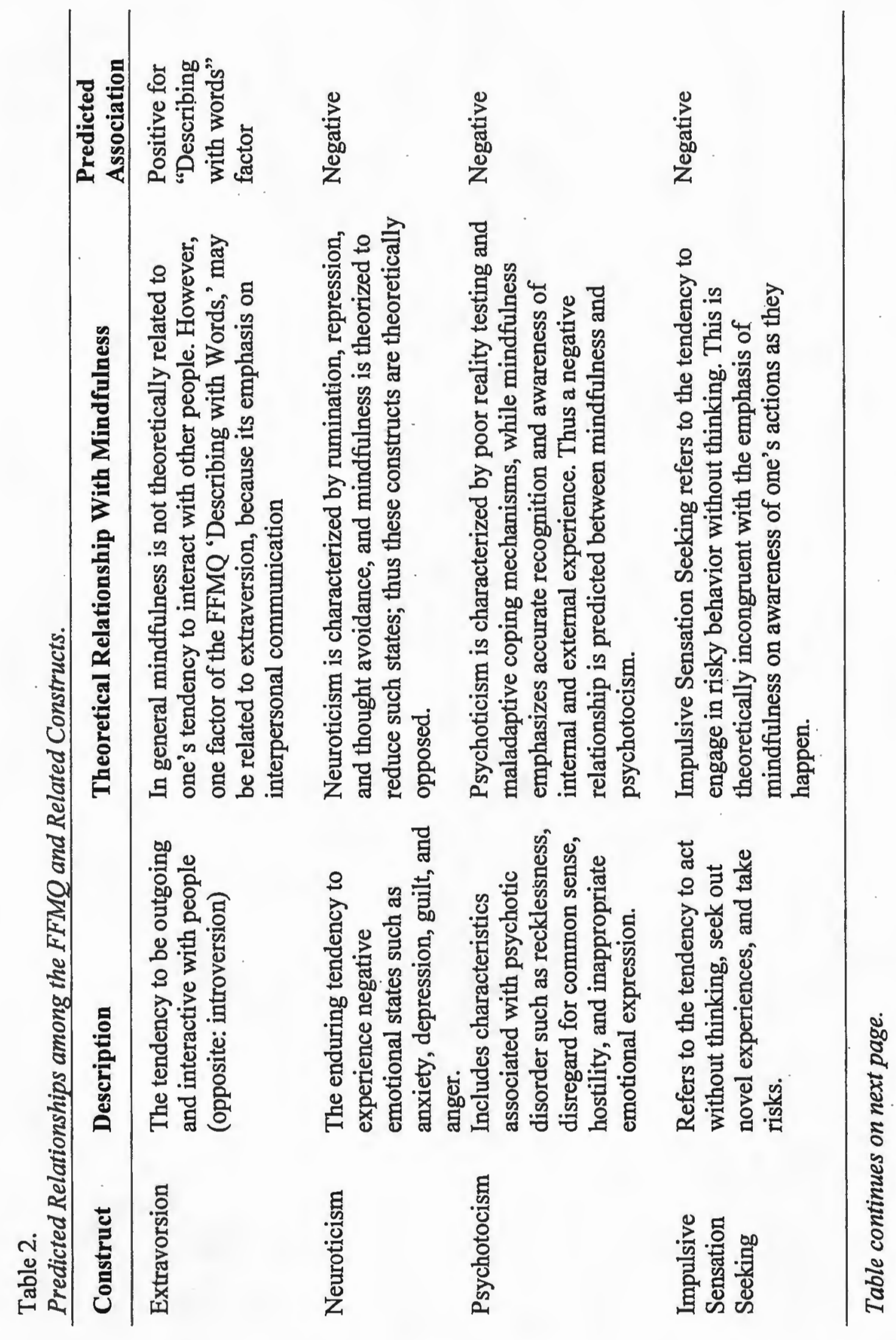




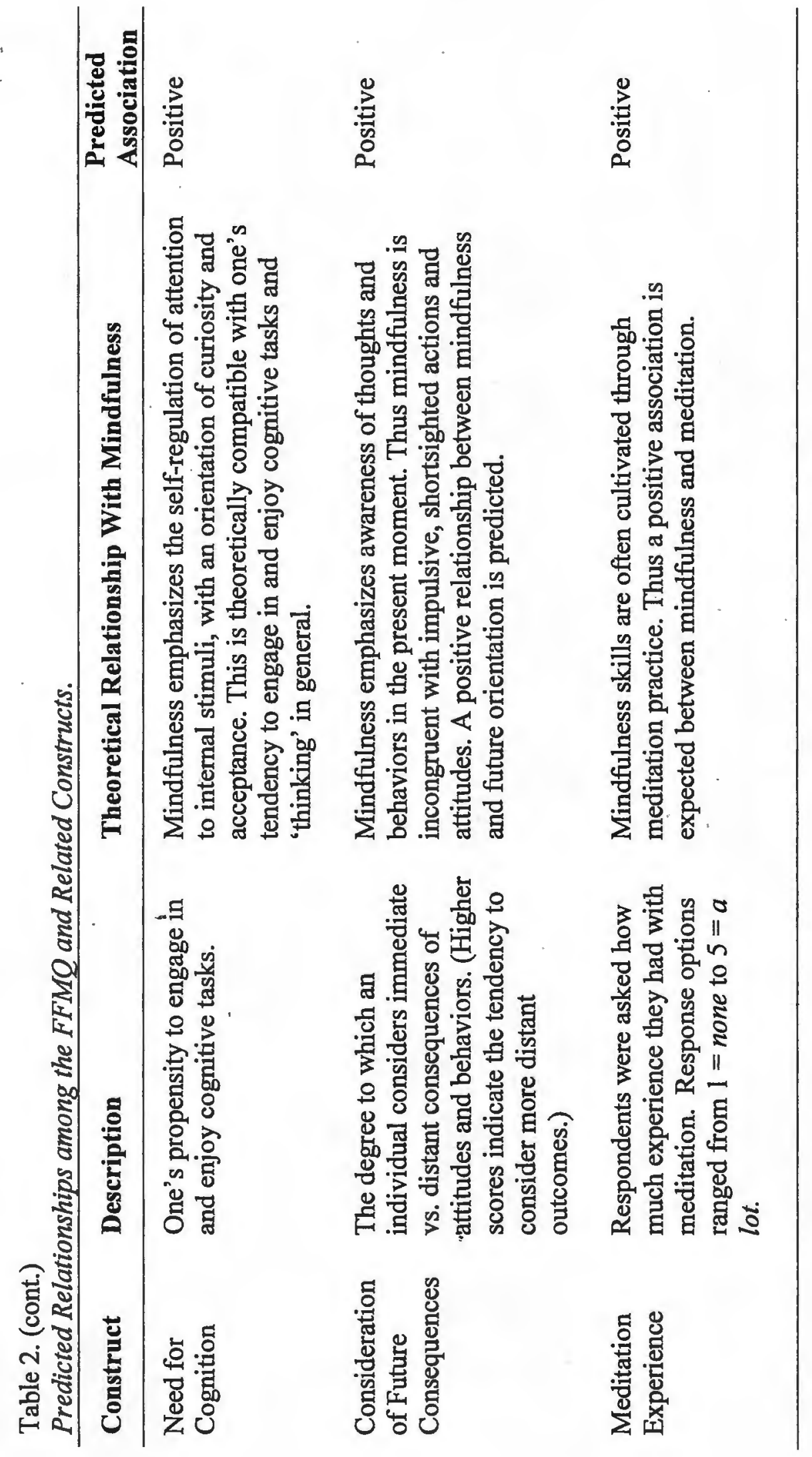




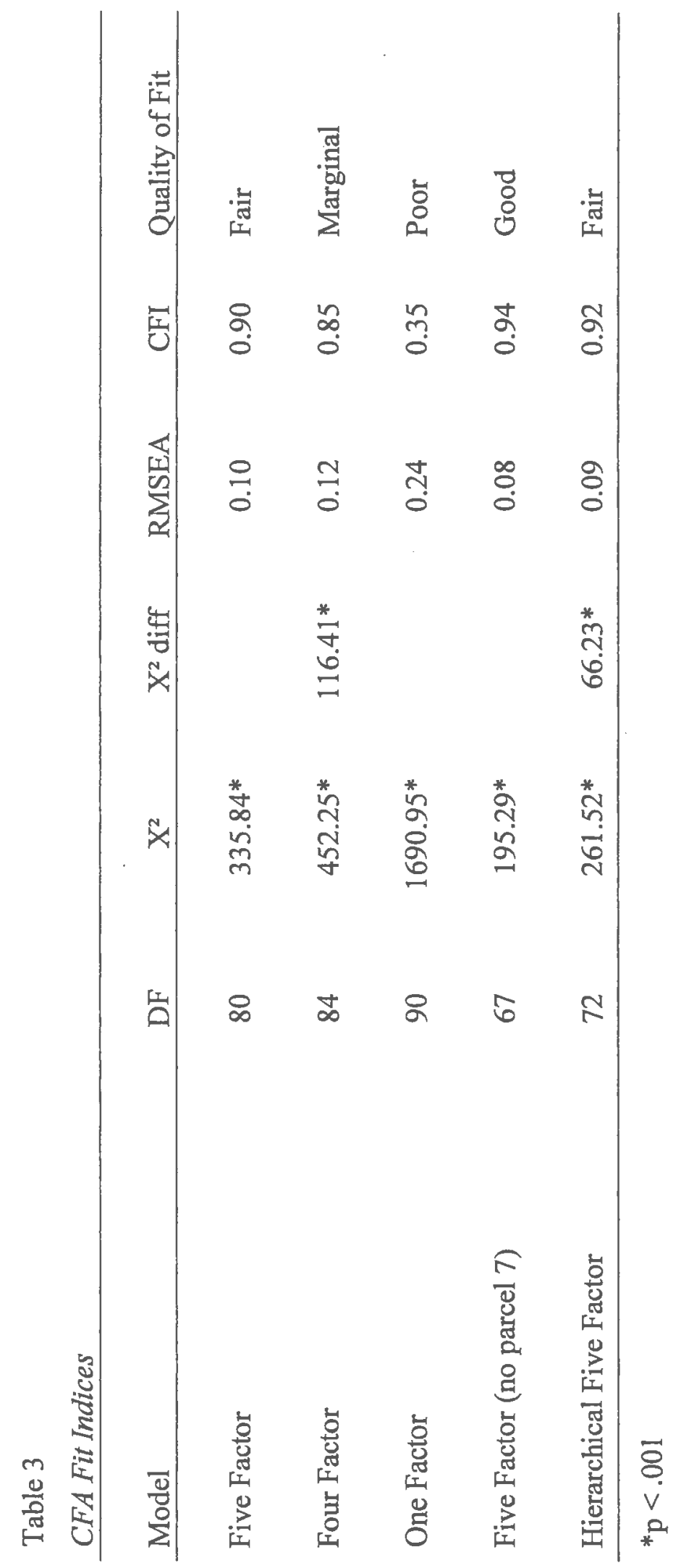




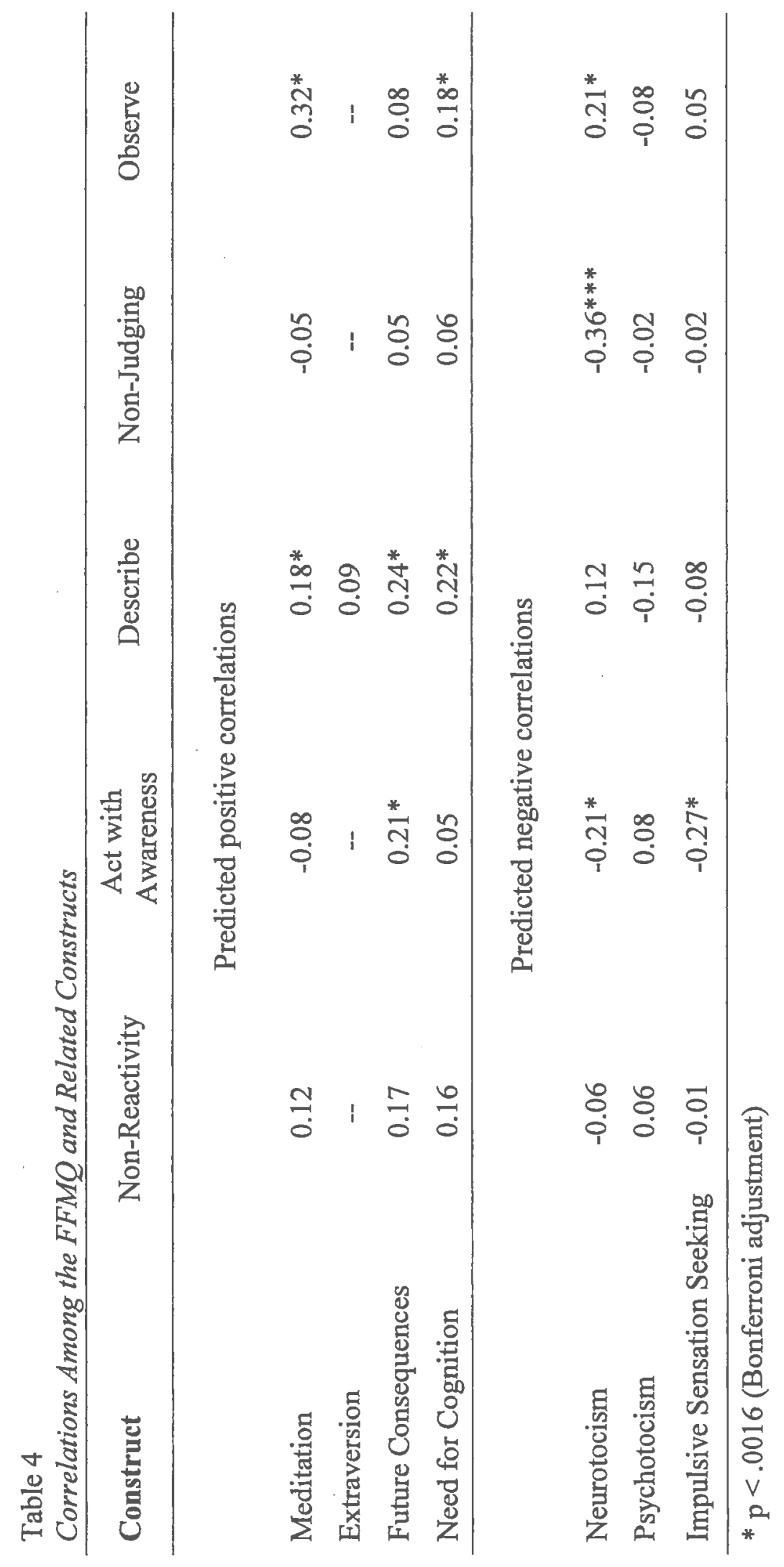




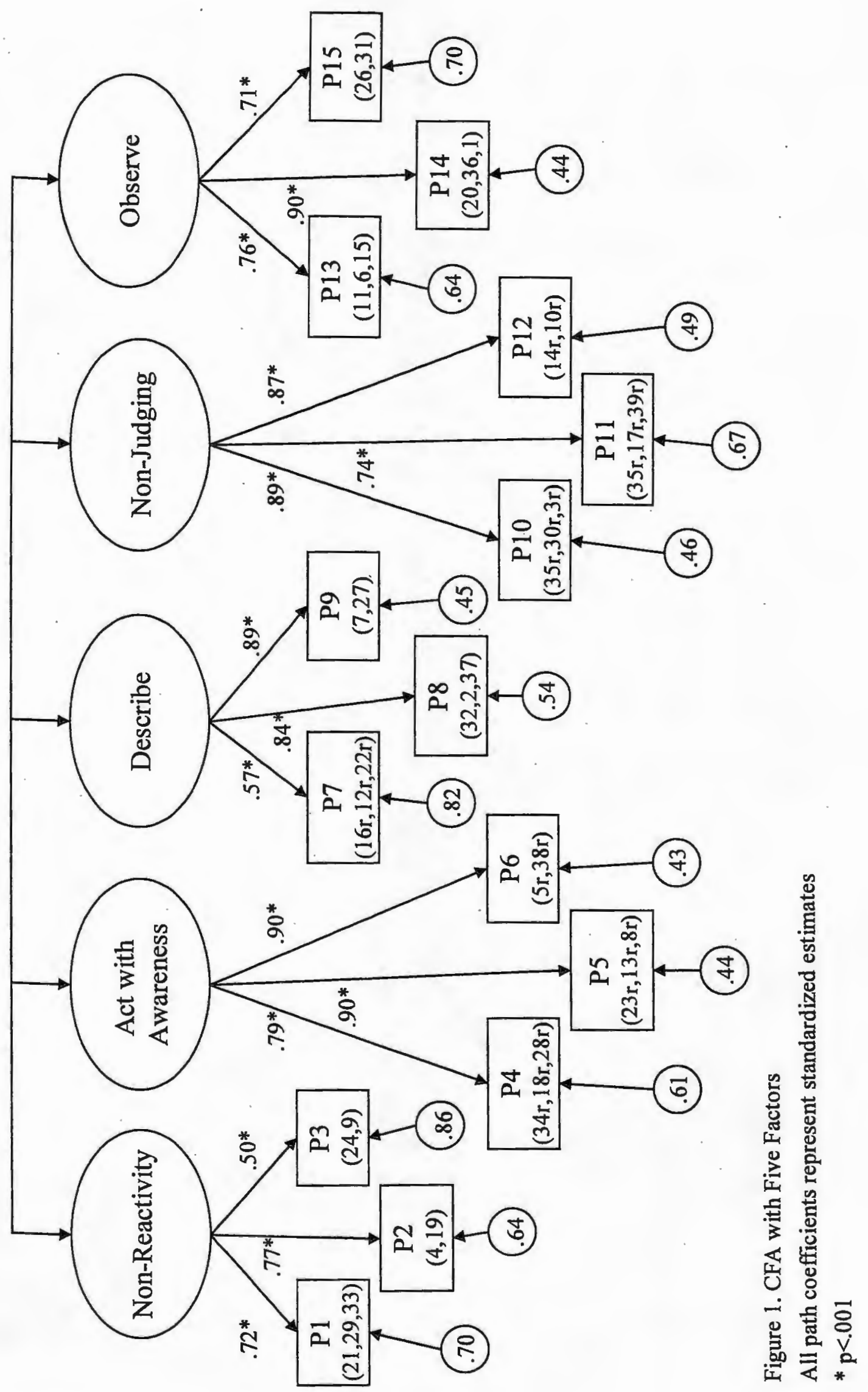




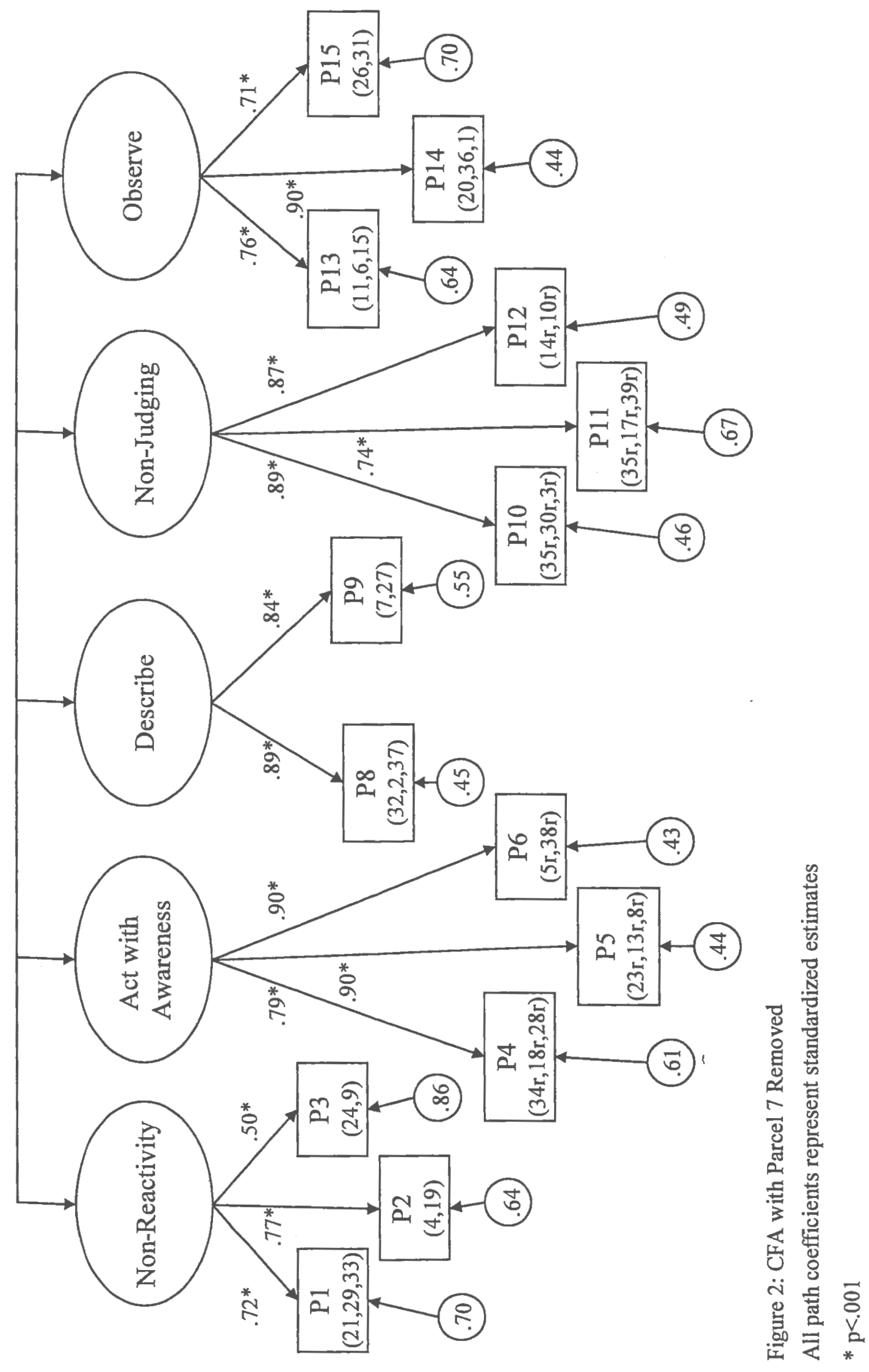




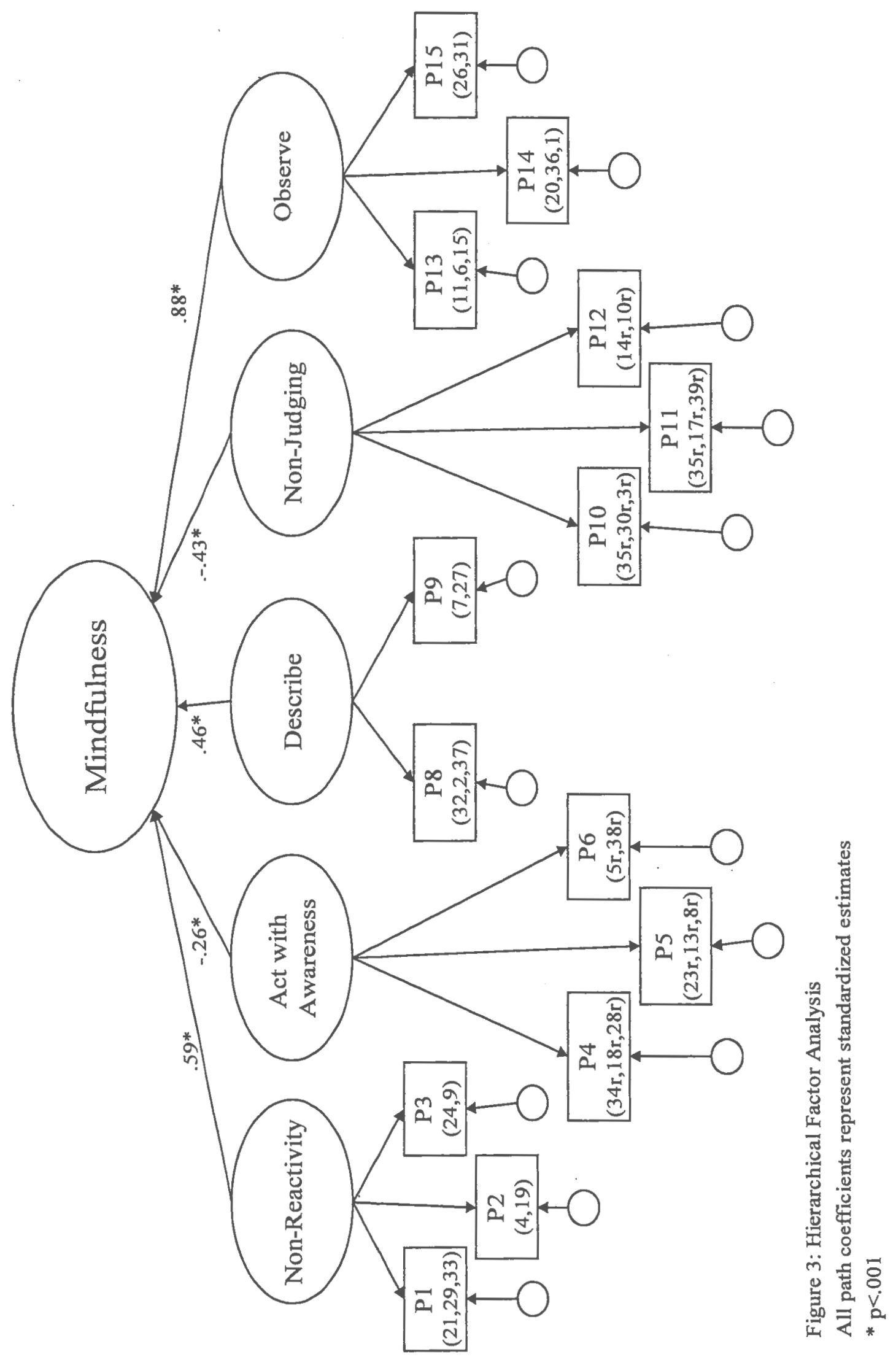




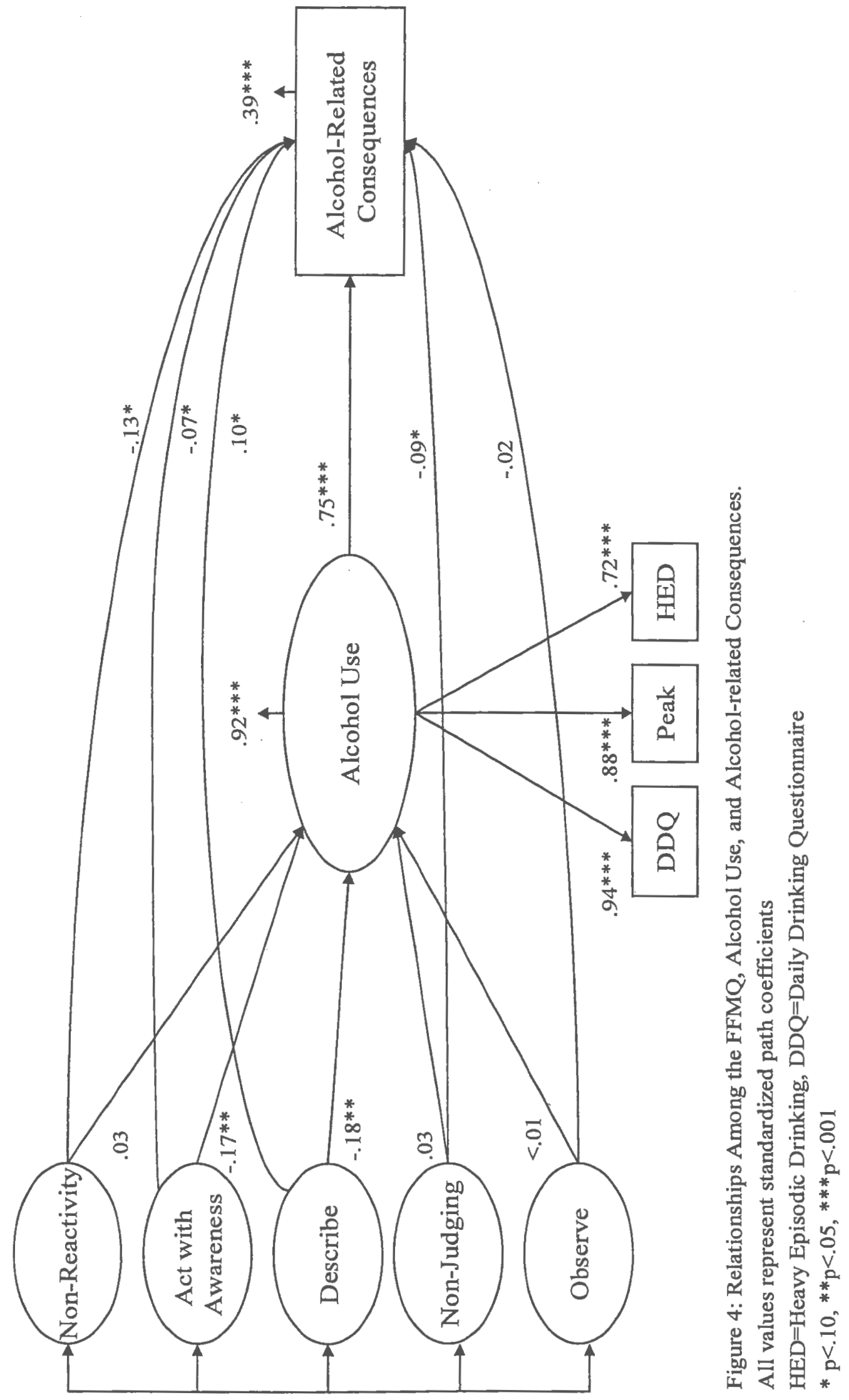




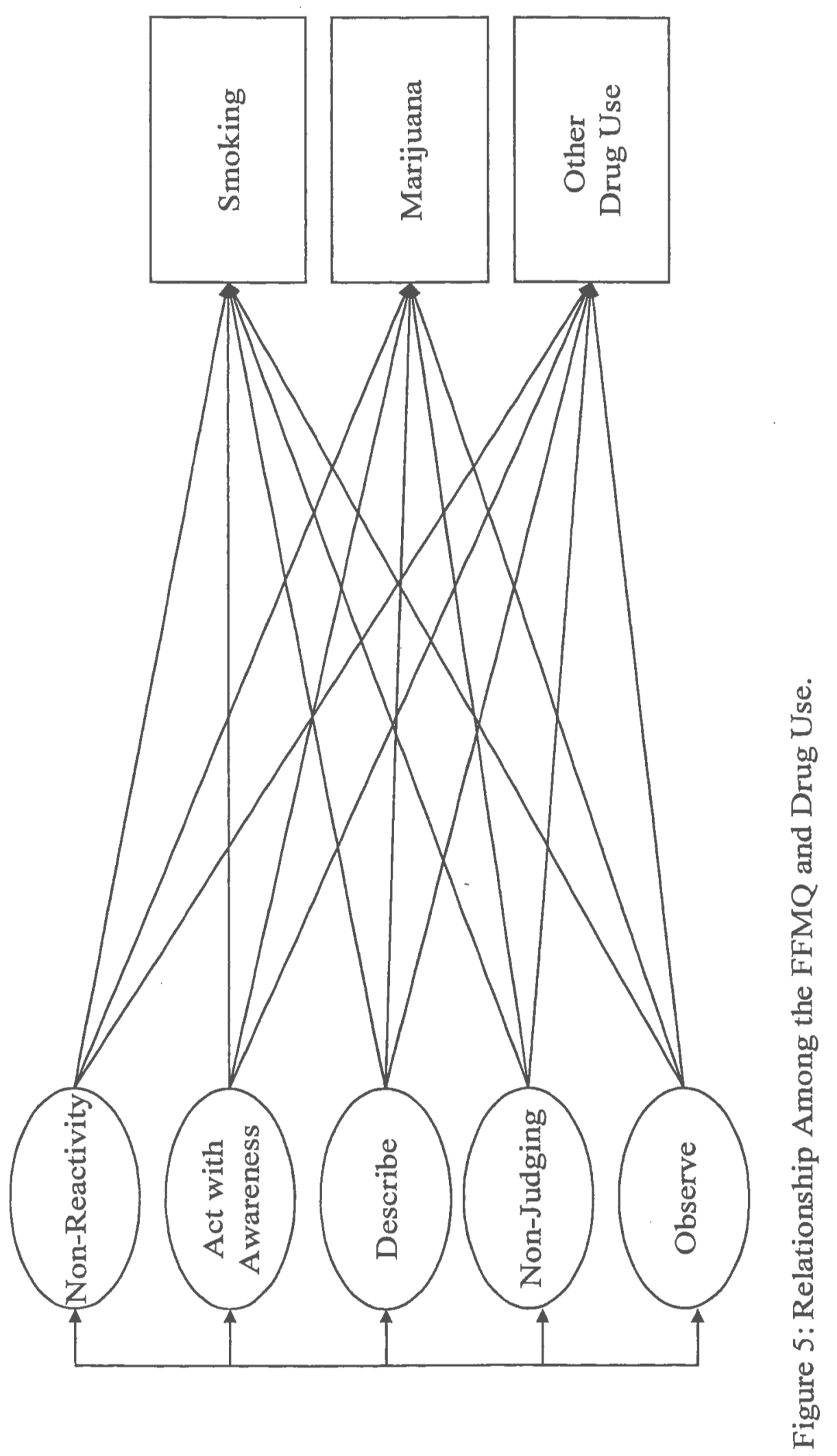




\section{Bibliography}

Alterman, A. I., Koppenhaver, J. M., Mulholland, E., Ladden, L. J., \& Baime, M. J. (2004). Pilot trial of effectiveness of mindfulness meditation for substance abuse patients. Journal of Substance use, 9(6), 259-268.

Baer, R. A., Smith, G. T., \& Allen, K. B. (2004). Assessment of mindfulness by selfreport: The kentucky inventory of mindfulness skills. Assessment, 11(3), 191-206.

Baer, R. A., Smith, G. T., Hopkins, J., Krietemeyer, J., \& Toney, L. (2006). Using self-report assessment methods to explore facets of mindfulness. Assessment, 13(1), 27-45.

Bazana, P. G., \& Stelmack, R. M. (2004). Stability of personality across the life span: A meta-analysis. New York, NY, US: Elsevier Science.

Bishop, S. R. (2002). What do we really know about mindfulness-based stress reduction? Psychosomatic Medicine, 64(1), 71-83.

Bishop, S. R., Lau, M., Shapiro, S., Carlson, L., Anderson, N. D., Carmody, J., et al. (2004). Mindfulness: A proposed operational definition. Clinical Psychology: Science and Practice, 11(3), 230-241.

Bollen, K. A. (1989). A new incremental fit index for general structural equation models. Sociological Methods and Research, 17, 303-316.

Bowen, S., Witkiewitz, K., Dillworth, T. M., Chawla, N., Simpson, T. L., Ostafin, B. D., et al. (2006). Mindfulness meditation and substance use in an incarcerated population. Psychology of Addictive Behoviors, 20(3), 343-347.

Bowen, S., Witkiewitz, K., Dillworth, T. M., \& Marlatt, G. A. (2007). The role of thought suppression in the relationship between mindfulness mediation and alcohol use. Addictive Behaviors, 32(10), 2324-2328.

Breslin, F. C., Zack, M., \& McMain, S. (2002). An information-processing analysis of mindfulness: Implications for relapse prevention in the treatment of substance abuse. Clinical Psychology: Science and Practice, 9(3), 275-299.

Brown, K. W., \& Ryan, R. M. (2003). The benefits of being present: Mindfulness and its role in psychological well-being. Journal of Personality and Social Psychology, 84(4), 822-848.

Buchheld, N., Grossman, P., \& Walach, H. (2001). Measuring mindful-ness in insight meditation (vipassana) and meditation-based psychotherapy: The development of the freiburg mindfulness inventory (FMD. Journal of Meditation and Meditation Research, 1, 11-34. 
Cacioppo, J. T., \& Petty, R. E. (1982). The need for cognition. Journal of Personality and Social Psychology, 42(1), 116-131.

Cacioppo, J. T., Petty, R. E., Feinstein, J. A., \& Jarvis, W. B. G. (1996). Dispositional differences in cognitive motivation: The life and times of individuals varying in need for cognition. Psychological Bulletin, 119(2), 197-253.

Cacioppo, J. T., Petty, R. E., \& Kao, C. F. (1984). The efficient assessment of need for cognition. Journal of Personality Assessment, 48(3), 306-307.

Carlson, L. E., \& Brown, K. W. (2005). Validation of the mindful attention awareness scale in a cancer population. Journal of Psychosomatic Research, 58(1), 29-33.

Caruso, J. C., Witkiewitz, K., Belcourt-Dittloff, A., \& Gottlieb, J. D. (2001). Reliability of scores from the eysenck personality questionnaire: A reliability generalization study. Educational and Psychological Measurement, 61(4), 675689.

Clark, L. A., \& Watson, D. (1995). Constructing validity: Basic issues in objective scale development. Psychological Assessment.Special Issue: Methodological Issues in Psychological Assessment Research, 7(3), 309-319.

Cohen, J. (1992). A power primer. Psychological Bulletin, 112, 155-159.

Collins, R. L., Parks, G. A., \& Marlatt, G. A. (1985). Social determinants of alcohol consumption: The effects of social interaction and model status on the selfadministration of alcohol. Journal of Consulting and Clinical Psychology, 53(2), 189-200.

Comrey, A. L., \& Lee, H. B. (1992). A first course in factor analysis (2nd ed.). Hillsdale, NJ: Lawrence Erlbaum Associates.

Cordon, S. L., \& Finney, S. J. (2008). Measurement invariance of the mindful attention awareness scale across adult attachment style. Measurement and Evaluation in Counseling and Development, 40(4), 228-245.

Derogatis, L. R. (1992). The brief symptom inventory (BSI): Administration, scoring, and procedures manual $=I I$ (2nd ed.). Minneapolis, MN: National Computer Systems.

Dimeff, L. A., Baer, J. S., Kivlahan, D. R., \& Marlatt, G. A. (1999). Brief alcohol screening and intervention for college students (BASICS): $A$ harm reduction approach. New York, NY, US: Guilford Press.

Eisenman, R., Grossman, J. C., \& Goldstein, R. (1980). Undergraduate marijuana use as related to internal sensation novelty seeking and openness to experience. Journal of Clinical Psychology, 36(4), 1013-1019. 
Eysenck, H. J. (1988). Eysenck personality questionnaire-revised. San Diego, CA: Educational and Industrial Testing Services.

Eysenck, M. W. (1992). Anxiety: The cognitive perspective. Hillsdale, NJ, England: Lawrence Erlbaum Associates, Inc.

Feldman, G. C., Hayes, 'A. M., Kumar, S. M., \& Greeson, J. M. (2004). Development, factor structure, and initial validation of the cognitive and affective mindfulness scale. Unpublished manuscript.

Fidell, L. S., \& Tabachnick, B. G. (2003). Preparatory data analysis. In J. Schrinka, \& W. F. Velicer (Eds.), Handbook of psychology: Research methods in psychology, volume 2 (pp. 115-141). New York: John Wiley \& Sons.

Gorsuch, R. L. (1983). Factor analysis (2nd ed.). Hillsdale, NJ: Lawrence Elbaum Associates.

Grekin, E. R., Sher, K. J., \& Wood, P. K. (2006). Personality and substance dependence symptoms: Modeling substance-specific traits. Psychology of Addictive Behaviors, 20(4), 415-424.

Groves, P., \& Farmer, R. (1994). Buddhism and addictions. Addiction Research, 2(2), 183-194.

Guadagnoli, E., \& Velicer, W. F. (1988). Relation to sample size to the stability of component patterns. Psychological Bulletin, 103(2), 265-275.

Harned, M. S., Chapman, A. L., Dexter-Mazza, E. T., Murray, A., Comtois, K. A., \& Linehan, M. M. (2008). Treating co-occurring axis I disorders in recurrently suicidal women with borderline personality disorder: A 2-year randomized trial of dialectical behavior therapy versus community treatment by experts. Journal of Consulting and Clinical Psychology, 76(6), 1068-1075.

Hayes, S. C. (2004). Acceptance and commitment therapy, relational frame theory, and the third wave of behavioral and cognitive therapies. Behavior Therapy, 35(4), 639-665.

Hayes, S. C., Strosahl, K. D., \& Wilson, K. G. (1999). Acceptance and commitment therapy: An experiential approach to behavior change. New York, NY, US: Guilford Press.

Hoppes, K. (2006). The application of mindfulness-based cognitive interventions in the treatment of co-occurring addictive and mood disorders. CNS Spectrums, $11(11), 829-851$.

Hoyle, R. H. (1995). Structural equation modeling: Concepts, issues, and applications. Thoasand Oaks, CA: Sage Publications. 
Hurlbut, S. C., \& Sher, K. J. (1992). Assessing alcohol problems in college students. Journal of American College Health, 41(2), 49-58.

Jackson, K. M., Sher, K. J., \& Schulenberg, J. E. (2008). Conjoint developmental trajectories of young adult substance use. Alcoholism: Clinical and Experimental Research, 32(5), 723-737.

Johnston, L. D., O'Malley, P. M., Bachman, J. G., \& Schulenberg, J. E. (2007). Monitoring the future national survey results on drug use, 1975-2006. volume II: College students and adults ages 19-45 No. NIH Publication No. 07-6206). Bethesda, MD: National Institute of $n$ Drug Abuse.

Kabat-Zinn, J., Lipworth, L., \& Burney, R. (1985). The clinical use of mindfulness meditation for the self-regulation of chronic pain. Journal of Behavioral Medicine, 8(2), 163-190.

Kabat-Zinn, J., Massion, A. O., Kristeller, J., \& Peterson, L. G. (1992). Effectiveness of a meditation-based stress reduction program in the treatment of anxiety disorders. American Journal of Psychiatry, 149(7), 936-943.

Kline, R. B. (2005). In D. A. Kenny (Ed.), Principles and practice of structural equation modeling. New York, NY: Guilford Press.

Larimer, M. E., \& Cronce, J. M. (2002). Identification, prevention, and treatment: A review of individual-focused strategies to reduce problematic alcohol consumption by college students. Journal of Studies on Alcohol.Special Issue: College Drinking, what it is, and what do to about it: Review of the State of the Science, Suppl14(Supp114), 148-163.

Larimer, M. E., \& Cronce, J. M. (2007). Identification, prevention, and treatment revisited: Individual-focused college drinking prevention strategies 1999-2006. Addictive Behaviors, 32(11), 2439-2468.

Lau, M. A., Bishop, S. R., Segal, Z. V., Buis, T., Anderson, N. D., Carlson, L., et al. (2006). The toronto mindfulness scale: Development and validation. Journal of Clinical Psychology, 62(12), 1445-1467.

Leigh, J., Bowen, S., \& Marlatt, G. A. (2005). Spirituality, mindfulness and substance abuse. Addictive Behaviors, 30(7), 1335-1341.

Linehan, M. M. (1987). Dialectical behavior therapy for borderline personality disorder: Theory and method. Bulletin of the Menninger Clinic, 51(3), 261-276.

Linehan, M. M., Armstrong, H. E., Suarez, A., \& Allmon, D. (1991). Cognitivebehavioral treatment of chronically parasuicidal borderline patients. Archives of General Psychiatry, 48(12), 1060-1064. 
Little, T. D., Cunningham, W. A., Shahar, G., \& Widamon, K. F. (2002). To parcel or not to parcel: Exploring the questions, weighing the merits. Structural Equation Modeling, 9, 151-173.

Li-Tze, H., \& Bentler, P. M. (1995). Evaluating model fit. In R. H. Hoyle (Ed.), Structural equation modeling: Concepts, issues, and applications (pp. 76-99). Thousand Oaks, CA: Sage.

MacCallum, R. C., Widaman, K. F., Zhang, S., \& \& Hong, S. (1999). Sample size in factor analysis. Psychological Methods, 4, 84-99.

MacKillop, J., Mattson, R. E., MacKillop, E. J. A., Castelda, B. A., \& Donovick, P. J. (2007). Multidimensional assessment of impulsivity in undergraduate hazardous drinkers and controls. Journal of Studies on Alcohol and Drugs, 68(6), 785-788.

MacKinnon, D. P. (2008). Introduction to statistical mediation analysis. New York, NY: Erlbaum.

Mahathera, N. (1971). Guide through the abhidhamma-pitaka (3rd ed.). Kandy, Sri Lanka: Buddhist Publication Society.

Marlatt, G. A., \& Marques, J. K. (1977). Meditation, self-control, and alcohol use. In R. B. Stuart (Ed.), Behavioral self-management: Strategies, techniques, and outcomes (pp. 117-153). New York, NY: Brunner/Mazel.

Marlatt, G. A. (2002). Buddhist philosophy and the treatment of addictive behavior. Cognitive and Behavioral Practice, 9(1), 44-49.

Marsh, H. W., Balla, J. R., \& Hau, K. Y. (1996). An evaluation of incremental fit indices: A clarification of mathematical and empirical properties. In G. A. Marcoulides, \& R. E. Schumacker (Eds.), [Advanced structural equation modeling: Issues and techniques] (pp. 315-353).

Muthén, L.K. and Muthén, B.O. (2006), Mplus, Los Angeles: Muthén and Muthén.

Noar, S. M. (2003). The role of structural equation modeling in scale development. Sturctural Equation Modeling, 104(2), 622-647.

Nunnaly, J. C., \& Bernstein, I. H. (1994). Psychometric theory (3rd ed.). New York, NY: McGraw-Hill, Inc.

Raykov, T., \& Marcoulides, G. A. (2000). A first course in structural equation modeling. Mahwah, NJ: Lawrence Erlbaum Associates.

Reiss, S., Peterson, R. A., Gursky, M., \& McNally, R. J. (1986). Anxiety, sensitivity, anxiety frequency, and the prediction of fearfulness. Behoviour Research and Therapy, 24, 1-8. 
Roemer, L., \& Orsillo, S. M. (2003). Mindfulness: A promising intervention strategy in need of further study. Clinical Psychology: Science and Practice, 10(2), 172178.

Salmon, P. G., Santorelli, S. F., \& Kabat-Zinn, J. (1998). Intervention elements promoting adherence to mindfulness-based stress reduction programs in the clinical behavioral medicine setting. New York, NY, US: Springer Publishing Co.

Schuerger, J. M., Zarrella, K. L., \& Hotz, A. S. (1989). Factors that influence the temporal stability of personality by questionnaire. Journal of Personality and Social Psychology, 56(5), 777-783.

Segal, Z. V., Teasdale, J. D., \& Williams, J. M. G. (2004). Mindfulness-based cognitive therapy: Theoretical rationale and empirical status. New York, NY, US: Guilford Press.

Segal, Z. V., Williams, J. M. G., \& Teasdale, J. D. (2002). Mindfulness-based cognitive therapy for depression: A new approach to preventing relapse. New York, NY, US: Guilford Press.

Shapiro, S. L., Bootzin, R. R., Figueredo, A. J., Lopez, A. M., \& Schwartz, G. E. (2003). The efficacy of mindfulness-based stress reduction in the treatment of sleep disturbance in women with breast cancer: An exploratory study. Journal of Psychosomatic Research, 54(1), 85-91.

Shapiro, S. L., Schwartz, G. E., \& Bonner, G. (1998). Effects of mindfulness-based stress reduction on medical and premedical students. Journal of Behavioral Medicine, 21(6), 581-599.

Sher, K. J., Wood, M. D., Crews, T. M., \& Vandiver, P. A. (1995). The tridimensional personality questionnaire: Reliability and validity studies and derivation of a short form. Psychological Assessment, 7(2), 195-208.

Smith, G. T., \& McCarthy, D. M. (1995). Methodological considerations in the refinement of clinical assessment instruments. Psychological Assessment.Special Issue: Methodological Issues in Psychological Assessment Research, 7(3), 300308.

Speca, M., Carlson, L. E., Goodey, E., \& Angen, M. (2000). A randomized, wait-list controlled clinical trial: The effect of a mindfulness meditation-based stress reduction program on mood and symptoms of stress in cancer outpatients. Psychosomatic Medicine, 62(5), 613-622.

Strathman, A., Gleicher, F., Boninger, D. S., \& Edwards, C. S. (1994). The consideration of future consequences: Weighing immediate and distant outcomes of behavior. Journal of Personality and Social Psychology, 66(4), 742-752. 
Teasdale, J. D., Moore, R. G., Hayhurst, H., Pope, M., Williams, S., \& Segal, Z. V. (2002). Metacognitive awareness and prevention of relapse in depression: Empirical evidence. Journal of Consulting and Clinical Psychology, 70(2), 275 287.

Teasdale, J. D., Segal, Z. V., Williams, J. M. G., Ridgeway, V. A., Soulsby, J. M., \& Lau, M. A. (2000). Prevention of relapse/recurrence in major depression by mindfulness-based cognitive therapy. Journal of Consulting and Clinical Psychology, 68(4), 615-623.

Tull, M. T., Rodman, S. A., \& Roemer, L. (2008). An examination of the fear of bodily sensations and body hypervigilance as predictors of emotion regulation difficulties among individuals with a recent history of uncued panic attacks. Journal of Anxiety Disorders, 22(4), 750-760.

Turrisi, R., Jaccard, J., Taki, R., Dunnam, H., \& Grimes, J. (2001). Examination of the short-term efficacy of a parent intervention to reduce college student drinking tendencies. Psychology of Addictive Behaviors.Special Issue: Understanding Binge Drinking, 15(4), 366-372.

Twohig, M. P., Shoenberger, D., \& Hayes, S. C. (2007). A preliminary investigation of acceptance and commitment therapy as a treatment for marijuana dependence in adults. Journal of Applied Behavior Analysis, 40(4), 619-632.

Walach, H., Buchheld, N., Buttenmüller, V., Kleinknecht, N., \& Schmidt, S. (2006). Measuring mindfulness--the freiburg mindfulness inventory (FMI). Personality and Individual Differences, 40(8), 1543-1555.

Wechsler, H., \& Nelson, T. F. (2008). What we have learned from the harvard school of public health college alcohol study: Focusing attention on college student alcohol consumption and the environmental conditions that promote it. Journal of Studies on Alcohol and Drugs, 69(4), 481-490.

Weissbecker, I., Salmon, P., Studts, J. L., Floyd, A. R., Dedert, E. A., \& Sephton, S. E. (2002). Mindfulness-based stress reduction and sense of coherence among women with fibromyalgia. Journal of Clinical Psychology in Medical Settings, 9(4), 297-307.

Weitzman, E. R., \& Nelson, T. F. (2004). College student binge drinking and the "prevention paradox": Implications for prevention and harm reduction. Journal of Drug Education, 34(3), 247-265.

Williams, J. M. G., Russell, I., \& Russell, D. (2008). Mindfulness-based cognitive therapy: Further issues in current evidence and future research. Journal of Consulting and Clinical Psychology, 76(3), 524-529.

Witkiewitz, K., Marlatt, G. A., \& Walker, D. (2005). Mindfulness-based relapse prevention for alcohol and substance use disorders. Journal of Cognitive 
Psychotherapy.Special Issue: State-of-the-Art in Behavioral Interventions for Substance use Disorders, 19(3), 211-228.

Wood, M. D., Read, J. P., Palfai, T. P., \& Stevenson, J. F. (2001). Social influence processes and college student drinking: The mediational role of alcohol outcome expectations. Journal of Studies on Alcohol, 62(1), 32-43.

Zucker, R. A., Donovan, J. E., Masten, A. S., Mattson, M. E., \& Moss, H. B. (2008). Early developmental processes and the continuity of risk for underage drinking and problem drinking. Pediatrics, 121 (Supplement 4), S252-S272.

Zuckerman, M., \& Cloninger, C. R. (1996). Relationships between cloninger's, zuckerman's, and eyesenck's dimensions of personality. Personality and Individual Differences, 21(2), 283-285.

Zuckerman, M., Kuhlman, D. M., Joireman, J., Teta, P., \& Kraft, M. (1993). A comparison of three structural models for personality: The big three, the big five, and the alternative five. Journal of Personality and Social Psychology, 65(4), 757-768. 